\title{
Secondary initiation of multiple bands of cumulonimbus over southern Britain. I: An observational case-study
}

\author{
By C. J. MORCRETTE ${ }^{1 *}$, K. A. BROWNING ${ }^{1}$, A. M. BLYTH ${ }^{2}$, K. E. BOZIER ${ }^{3}$, \\ P. A. CLARK ${ }^{4}$, D. LADD ${ }^{5}$, E. G. NORTON ${ }^{6}$ and E. PAVELIN ${ }^{1}$ \\ ${ }^{1}$ Department of Meteorology, University of Reading, UK \\ ${ }^{2}$ School of Earth and Environment, University of Leeds, UK \\ ${ }^{3}$ Centre for Environmental Systems Research, University of Salford, UK \\ ${ }^{4}$ Met Office, JCMM, University of Reading, UK \\ ${ }^{5}$ Chilbolton Observatory, Rutherford Appleton Laboratory, UK \\ ${ }^{6}$ Department of Physics, University of Wales, Aberystwyth, UK
}

(Received 18 July 2005; revised 5 December 2005)

\section{SUMMARY}

Special observing facilities have been assembled in southern England as part of the Convective Storm Initiation Project (CSIP) to study the mesoscale and convective-scale processes that determine precisely where warm-season convective showers will break out. This paper reports the results of a case-study during the pilot field campaign of CSIP in July 2004. One purpose of the pilot project was to demonstrate the value of various observational facilities and to evaluate the usefulness of a variety of analysis and synthesis techniques. Amongst other things, the case-study demonstrates the utility of high-resolution imagery from the Meteosat Second Generation satellite for tracking the early stages of the convective clouds, and of a new clear-air scanning radar at Chilbolton for mapping both the top of the boundary layer and the initial growth of the convective cells that penetrate it. The particular event studied involved the triggering of convection that developed into three parallel arcs of showers and thunderstorms. The first arc was triggered along the leading edge of the outflow (density current) from an earlier cluster of showers, but the convection in the second and third arcs was triggered by a different mechanism. The paper describes in detail the way in which this convection broke through the stable layer, or lid, at the top of a boundary layer of variable depth. The strength of the lid decreased and the depth of the boundary layer increased with time as a result of diurnal heating, but the precise locations where convection finally broke through were determined by the spatial variability in boundary-layer depth. The analysis suggests that a wave-like modulation of the boundary-layer depth of amplitude $150 \mathrm{~m}$, perhaps due to a gravity-wave disturbance from the earlier cluster of showers, had a greater influence on where the convection was triggered than the modest hills (typically $200 \mathrm{~m}$ high) in southern England.

\section{KEYWORDS: Density current Gravity waves Radar Satellite imagery}

\section{INTRODUCTION}

Forecasting convective precipitation is important because of the need to minimize the damage and disruption sometimes caused by associated flash floods and strong winds. Although current numerical weather-prediction (NWP) models have skill in forecasting the regional location of heavy convective showers and thunderstorms, they are unable to predict the precise location and timing of convective initiation. This has motivated the establishment of a project called the Convective Storm Initiation Project (CSIP), which is a collaborative project between groups within several British universities under the aegis of the Universities' Facility for Atmospheric Measurement (UFAM) and the Met Office. The universities involved are Aberystwyth, Leeds, Manchester, Reading and Salford. The aim of CSIP is to understand better the mechanisms responsible for the initiation of convective precipitation in a maritime extratropical environment such as the United Kingdom. In order to achieve this goal, a special observational programme is being conducted, during which the very early stages in the development of convective showers are studied. This information is intended to help in the validation and development of high-resolution versions of the Met Office's NWP model, with the

* Corresponding author: Department of Meteorology, University of Reading, Earley Gate, PO Box 243, Reading RG6 6BB, UK. e-mail: c.j.morcrette@ reading.ac.uk

(c) Royal Meteorological Society, 2006. The contribution of P. A. Clark is Crown copyright. 
goal of improving the accuracy and specificity of forecasts of such events. The structure and evolution of convective clouds, the complex microphysical processes that occur within them, and the organization of convective clouds into long-lived systems such as mesoscale convective systems, are all important topics and areas of active research; however, CSIP concentrates just on the very early stages of precipitating convection, in order to understand the mechanisms leading to the initiation of convective showers. This was also a key objective of the IHOP-2000 project in the Midwest of the United States (Weckwerth et al. 2004).

The general questions that CSIP aims to answer can be categorized into three areas: large-scale, small-scale, and feedback effects. Specific questions are:

(i) What are the synoptic and mesoscale processes that create regions amenable to convective initiation?

(ii) What are the significant localized perturbations in the boundary layer that trigger the initial convective cells (i.e. primary initiation) and what causes them? Possible candidates are humidity and temperature variations, and convergence, perhaps induced by topography or surface heterogeneity.

(iii) How do existing convective cells modify the atmosphere around them, and hence influence or even dominate the subsequent initiation of convection (i.e. secondary initiation)?

The main observational campaign occurred in June, July and August 2005 but a pilot campaign was held in July 2004 to test new instruments and procedures, during which several interesting meteorological events were observed. The observations made on 10 July 2004 are the subject of this paper.

This day featured several narrow bands of convective showers which led to shortlived yet heavy rainfall, with some lightning, over parts of southern England. The purpose of this paper is, in addition to demonstrating the utility of various observational facilities and data analysis/synthesis procedures, to describe the evolution in the structure of the environment and the early stages of the rain bands on 10 July with the aim of explaining how and why multiple rain bands formed where they did. The instruments deployed during the CSIP pilot campaign and the routine data sources complementing them are described in section 2 . The observations themselves are presented in section 3 . The discussion is in section 4. Finally a summary of the issues raised during the observational analysis, and which need to be addressed using numerical modelling, is given in section 5 .

\section{DATA}

Figure 1 shows the location of the various facilities used during the CSIP pilot project in July 2004. To assist in the conduct of the project, a forecast centre was set up in the Joint Centre for Mesoscale Meteorology (JCMM) at the University of Reading where the forecast products from the Met Office in Exeter could be viewed alongside nowcast products from radar, satellite and in situ measurements.

The CSIP field campaigns are based in southern Britain, with the focus being on the area covered by the two radars on the large scanning dish at Chilbolton, Hampshire. One of the radars mounted on the $25 \mathrm{~m}$ diameter antenna is a $10 \mathrm{~cm}(3 \mathrm{GHz}, \mathrm{S}$ band) polarized Doppler radar (Goddard et al. 1994) which provides measurements of reflectivity, radial velocity, differential reflectivity, depolarization ratio and differential phase to a range of $95 \mathrm{~km}$, corresponding to the large circle in Fig. 1. This radar will henceforth be referred to as the 'rain radar'. A new $23.5 \mathrm{~cm}(1275 \mathrm{MHz}$, L band) clear-air radar was 


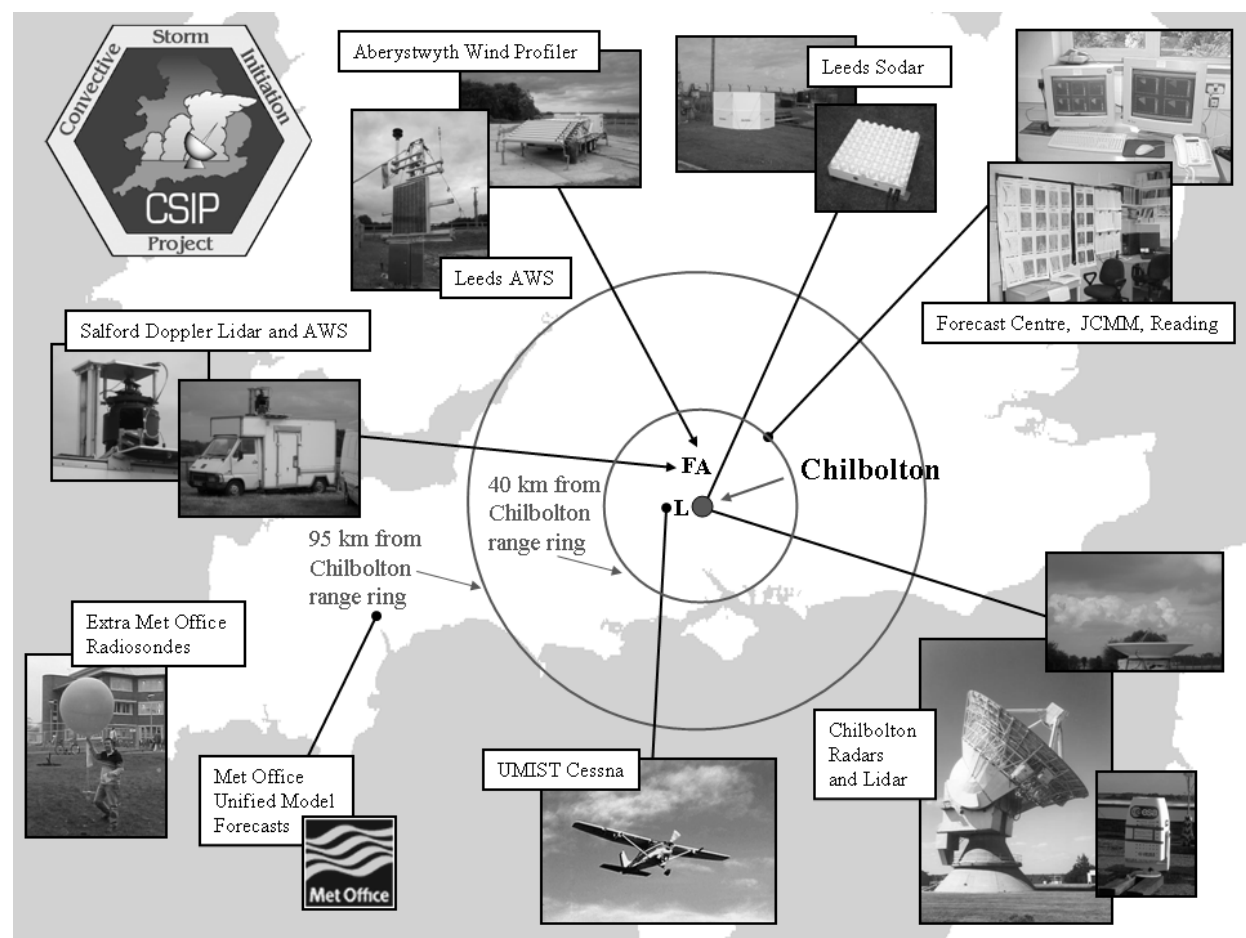

Figure 1. The location of the facilities used during the CSIP pilot campaign in July 2004. The campaign was based at Chilbolton, from which $40 \mathrm{~km}$ and $95 \mathrm{~km}$ range rings are shown. F, A and L give the locations of Faccombe, Ashmansworth and Larkhill.

installed along with the rain radar, on the same $25 \mathrm{~m}$ antenna in 2003, allowing clear-air (and in-cloud) Bragg scatter measurements to be made at the same time as Rayleigh scatter precipitation measurements. This new radar will be referred to here as the "clearair radar'. During the pilot project, the clear-air radar had a maximum range of around $40 \mathrm{~km}$, corresponding to the smaller circle in Fig. 1. It is capable of mapping the tops of the boundary layer and of individual convective elements rising above it, by detecting the strong refractive index inhomogeneities at their boundaries. These are later referred to as Type 1 (Bragg scattering) echoes to distinguish them from so-called Type 2 (Rayleigh scattering) echoes due to precipitation. The Chilbolton clear-air radar is also capable of measuring the changes in the refractive index along paths hitting ground targets, allowing the horizontal variations in humidity to be calculated using the refractivity technique described by Fabry et al. (1997). Various other instruments permanently based at Chilbolton were operated during the campaign. These include a vertically pointing $8.6 \mathrm{~mm}(35 \mathrm{GHz}, \mathrm{Ka}$ band) cloud radar, a vertically pointing $905 \mathrm{~nm}$ lidar, standard surface meteorological instruments, some rain-gauges, a cloud camera and a webcam. The University of Leeds also operated one of the UFAM sodars at Chilbolton.

The UFAM $23 \mathrm{~cm}(1290 \mathrm{MHz}$, L band) wind profiler, operated by the University of Wales, Aberystwyth, henceforth the 'wind profiler', was located at Ashmansworth, $20 \mathrm{~km}$ north of Chilbolton. Like the clear-air radar at Chilbolton, it obtains returns by Bragg scattering from refractive index inhomogeneities and Rayleigh scattering from precipitation particles. It employs three beams to measure different velocity components as well as the signal strength (Norton et al. 2005). An automatic weather station (AWS) 
operated by the University of Salford was located at Faccombe, not far from the wind profiler. Several other UFAM instruments were used during the pilot campaign, but did not operate on 10 July. These include the meteorologically instrumented Cessna aircraft operated by the University of Manchester, the scanning Doppler lidar operated by the University of Salford, and an AWS operated by the University of Leeds. Additional radiosondes were launched at non-standard times from Met Office stations but these were also unavailable on 10 July.

The analysis presented in this paper also makes use of some routinely available observations. These consist of high-resolution visible and infrared imagery, both available every 15 minutes, from Meteosat- 8 . This is the Meteosat Second Generation (MSG) satellite located in geostationary orbit over the Greenwich meridian (Schmetz et al. 2002). The high-resolution visible channel has pixels of $1 \mathrm{~km}$ width at the subsatellite point. The infrared pixels are $3 \mathrm{~km}$ wide. A digital time-lapse camera was also operated at Chilbolton to capture the visual appearance of the clouds from ground level. Data from radiosondes launched operationally from Herstmonceux and rain-rate observed by the weather radar network were also used, as were forecast data from the operational version of the Met Office's mesoscale model in order to produce modelderived soundings for a location near to Chilbolton. The model used a $12 \mathrm{~km}$ grid and the forecast was started from 0000 UTC on 10 July 2004.

\section{REsults}

We begin, in section 3(a), with a broad-scale overview and then look at the life-cycle of the convective system that formed early in the morning on 10 July 2004 (section 3(b)). In section 3(c) we look at the gust front associated with one of the several arcs of precipitation. Then we analyse the evolution of the vertical structure of the atmosphere (section 3(d)) and the systematic spatial variation in the depth of the boundary layer during the initiation of one of the arcs of convective clouds (section 3(e)). Finally, we examine the extent to which the topography may have affected the triggering of convection (section 3(f)).

\section{(a) Broad-scale overview}

Figure 2 shows the operational surface analysis at 0600 UTC on 10 July 2004, just before the outbreak of convection in southern Britain. An upper-level short-wave trough is marked in Fig. 2 extending from the south-western tip of Ireland to south Wales. An irregular band of precipitation associated with this feature moved southeastwards throughout the morning. Figure 3 shows that by 1200 UTC the precipitation associated with this trough had reached south Wales, and it extended north-eastwards into the Midlands. However, it is clearly separate from the system of multiple northsouth oriented bands of convective precipitation which developed to the south and east of it during the morning. It is part of this multiply banded system that is the focus of this study. The part to be investigated consists of three arcs of convective precipitation (labelled 1, 2 and 3 in Fig. 3). These arcs were not associated with the upper-level trough or any other synoptic feature; rather they initiated in the weakly baroclinic region present ahead of the trough.

Figure 4 shows soundings for the two Met Office sites, Herstmonceux $(\mathrm{H})$ and Larkhill (L), marked in Fig. 3. The Herstmonceux sounding launched at 1100 UTC (Fig. 4(a)) is representative of the environment just ahead of Arc 3 after it had been in existence for 2 hours. Radiosondes were not released from Larkhill on this occasion and so a model-derived sounding for Larkhill is used instead (Fig. 4(b)). 


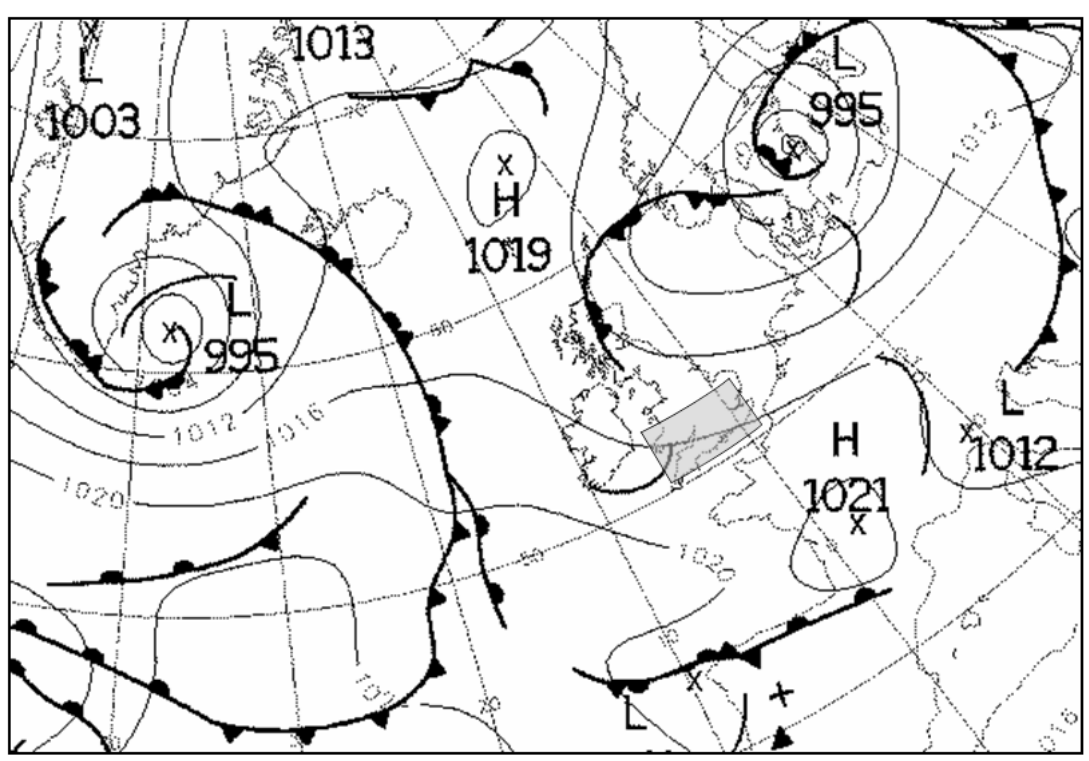

Figure 2. Met Office operational surface analysis for 0600 UTC on 10 July 2004 . The shaded box shows the area of Fig. 3 where the case-study is based.

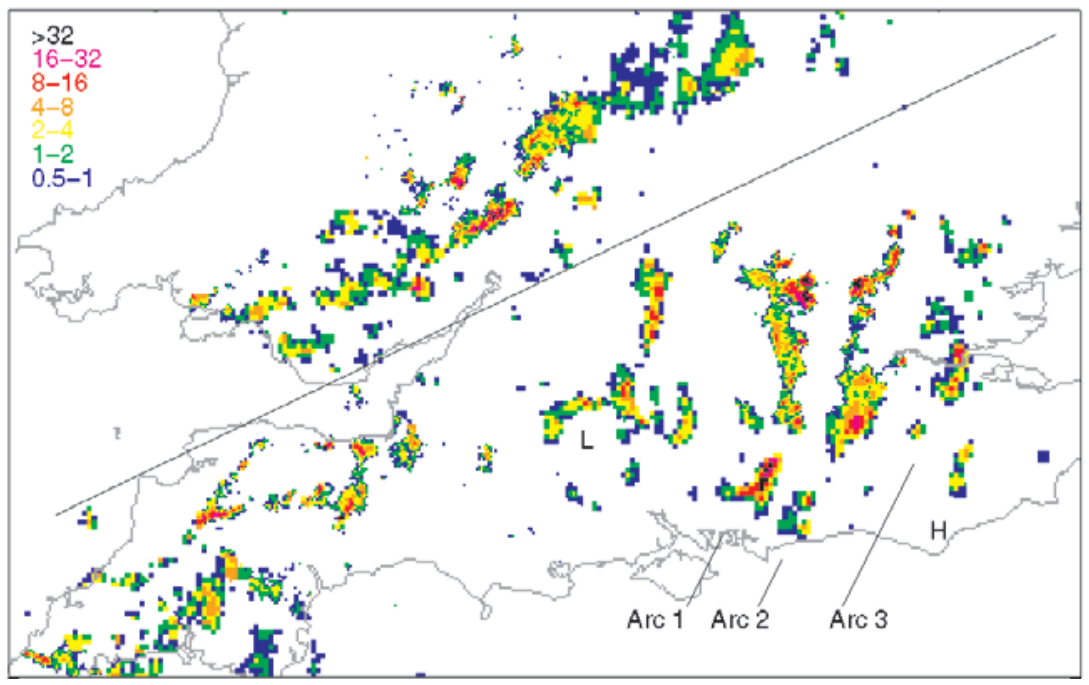

Figure 3. Rain-rate $\left(\mathrm{mm} \mathrm{h}^{-1}\right.$, see colour key) at $1200 \mathrm{UTC}$ on 10 July 2004 , derived from the weather radar network. Pixels are 1,2 , or $5 \mathrm{~km}$ square depending on the best resolution available at that location. The diagonal line distinguishes the area of convective outbreaks associated with the short-wave trough (to the north-west of it) from the arcs of showers that developed ahead of it. $\mathrm{H}$ and $\mathrm{L}$ show the locations of Herstmonceux and Larkhill, soundings for which are plotted in Fig. 4.

This is representative of the environment near Arc 2 when that arc of convection was initiating. The use of model-derived soundings in lieu of observations is justified by the good performance of the model on this day. These soundings are presented merely as an introductory overview to indicate that the atmosphere in the vicinity of the arc bands was weakly unstable, with convection possible up to about $550 \mathrm{hPa}$, given slight lifting 
Herstmonceux Rodiosonde
a) $10 / 07 / 2004 \quad 112$

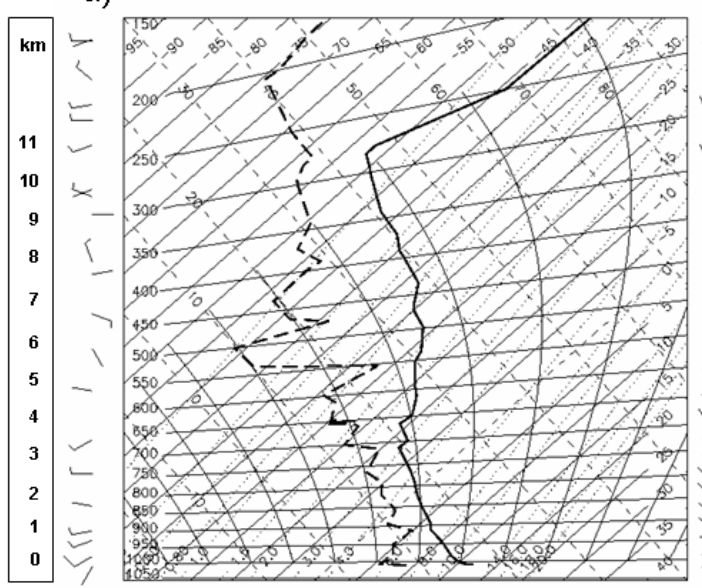

b) Data: Column from UM

L) Lat: 51.20 Lon: -1.80

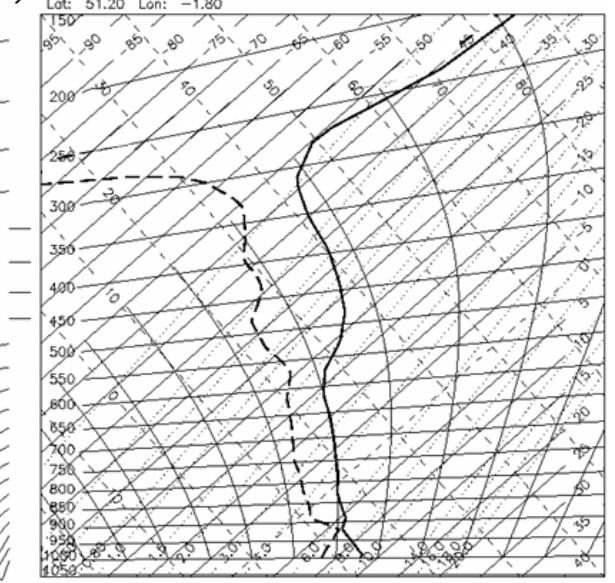

Figure 4. Tephigrams for radiosonde ascents on 10 July 2004 at (a) Herstmonceux at 1100 UTC and (b) Larkhill at 0900 UTC $(T+9)$ derived from the 0000 UTC run of the operational $12 \mathrm{~km}$ mesoscale model. An approximate height-scale is shown on the left.

or surface heating. A closer analysis of the model soundings for a succession of times is presented in section 4 and this suggests that the model was giving results consistent with the observed time of initiation of the convection. The wind sounding at the time of initiation (Fig. 4(b)) shows that the winds were from west to south-west at all levels below $500 \mathrm{hPa}$, with a maximum at about $900 \mathrm{hPa}$.

\section{(b) Life-cycle of the multiply banded convective system}

The system investigated in this paper had its origins in south Wales and travelled east-south-eastwards across southern England, heading towards Kent. The term 'system' used here refers to the three arcs of convective precipitation labelled in Fig. 3, together with an earlier cluster of convective showers referred to as the primary storm $(\mathrm{P})$ which had decayed by the time of Fig. 3 but which (as discussed later) appeared to play a role in triggering the arcs. A central portion of the system travelled within the shaded parallelogram in Fig. 5(f). Figures 5(a)-(e) show a series of 5 square regions, moving with the system, in which we look at the rainfall patterns derived from the radar network at key times in the evolution of the system. Figure 5(a) (for 0600 UTC) shows the early stage of the primary storm P, located in the Vale of Glamorgan in south Wales. The first shower echo was detected by the radar network at 0530 UTC, $8 \mathrm{~km}$ further west. By 0715 UTC (Fig. 5(b)), this shower is seen to have moved eastwards towards the Bristol Channel where it has merged with some other shower cells that had initiated over the Bristol Channel at 0645 UTC and it has been joined by another shower on the eastern shore of the Bristol Channel (indicated by a second P). For now we are interested in just the envelope of all these showers, which we will refer to collectively as the primary storm. The primary storm intensified as it moved eastwards, reaching its peak intensity between 0730 and 0800 UTC. It then began to decay and by 0845 UTC (Fig. 5(c)) there was just an area of mainly light rain situated south of Bristol. Of particular interest at this time are two new shower cells located between approximately $25 \mathrm{~km}$ east and $30 \mathrm{~km}$ north-east of the centre of this decaying residue of the primary storm. This was the beginning of Arc 1 . 

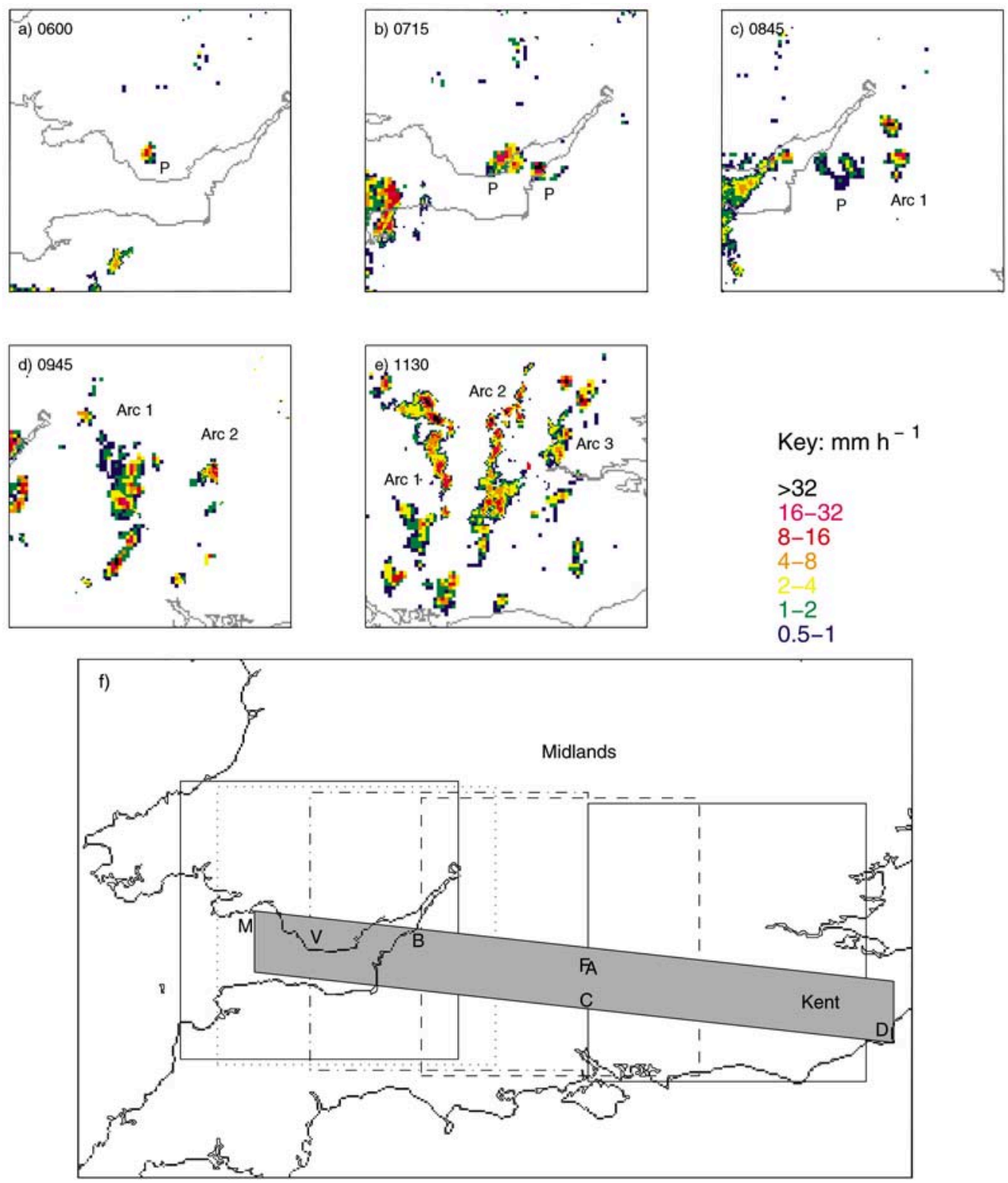

Figure 5. A sequence of maps of rain-rate over $150 \mathrm{~km} \times 150 \mathrm{~km}$ regions at (a) 0600 , (b) 0715 , (c) 0845 , (d) 0945 and (e) 1130 UTC, showing the evolution of Arcs 1, 2 and 3. The three Arcs developed during the period covered by (c), (d) and (e); the earlier so-called primary showers are labelled 'P'. (f) shows the various regions shown in (a) to (e) identified by the series of square frames. The shaded parallelogram shows the swath from The Mumbles (M) to Dungeness (D) used in deriving the Hovmüller diagrams in Figs. 8 and 9. V, B, F, A and C mark the locations of the Vale of Glamorgan, Bristol, Faccombe, Ashmansworth and Chilbolton.

The cloud cover at 0845 UTC, observed by the MSG high-resolution visible channel, is shown in Fig. 6(a). It shows some dull grey anvil cloud associated with the primary storm and some brighter, presumably more convectively active, clouds ahead of it associated with the new shower cells in Arc 1. By 0945 UTC (Fig. 6(b)) these new cells, and others triggered subsequently in their vicinity, have organized into a well-defined arc, with the primary storm at its focus, which by then appears as an increasingly small 

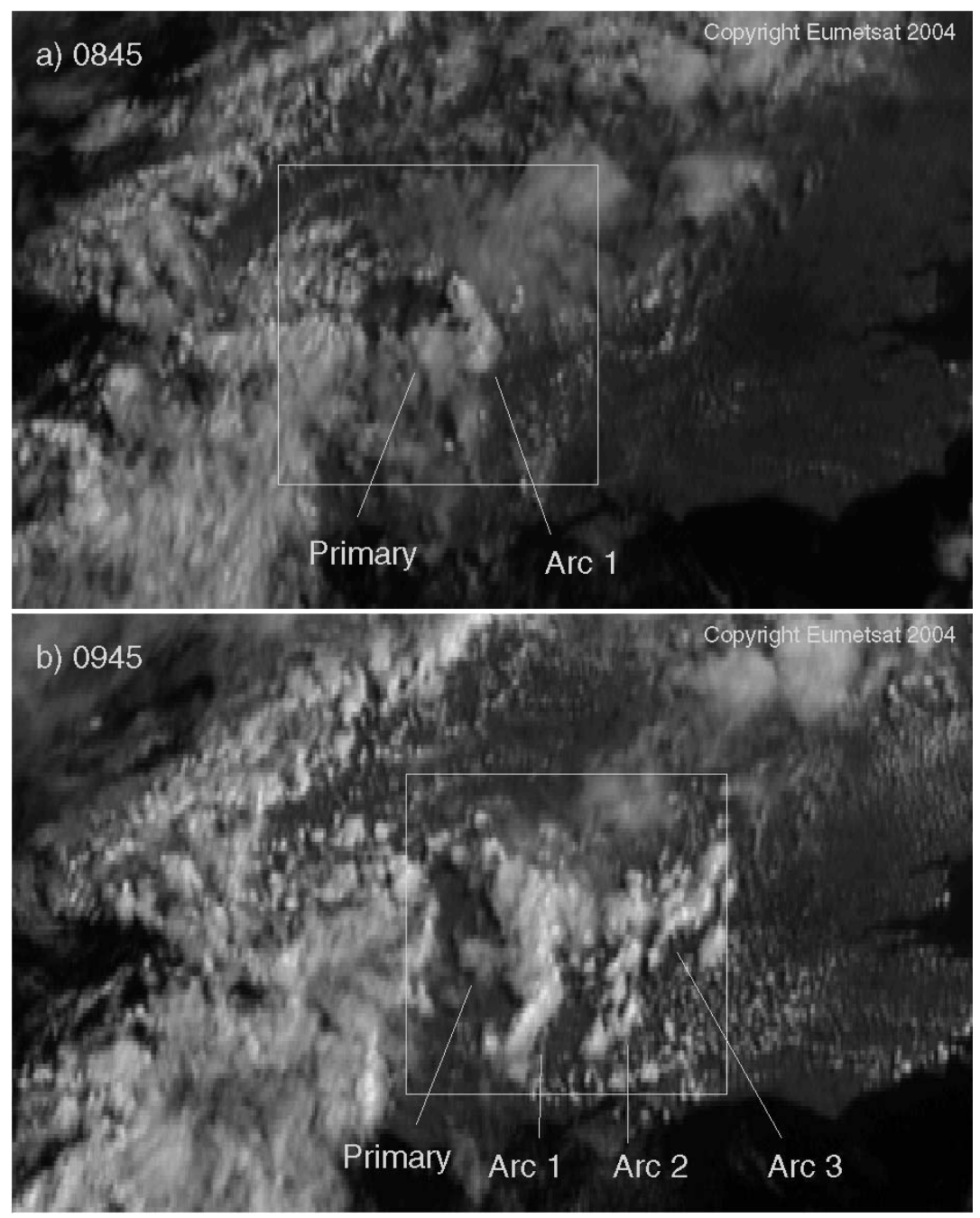

Figure 6. Meteosat-8 high-resolution visible images at (a) 0845 and (b) 0945 UTC. The overall area is the same as in Fig. 3. The $150 \mathrm{~km}$ squares correspond to the panels of radar data for 0845 and 0945 UTC shown in Figs. 5(c) and (d), respectively. Clouds associated with Arcs 1,2 and 3 and the primary storm are labelled accordingly.

grey area of cloud. Precipitation develops only in the leading portion of the arc; the other parts of the Arc 1 cloud are associated with a trailing anvil due to the rearwardflowing storm-relative outflow aloft. The cloud band associated with Arc 1 subsequently travelled eastwards as shown by the series of tracings in Fig. 7. This figure shows the arc cloud expanding radially outwards from an apparent source corresponding to the primary storm. An AWS operated by the Met Office at Filton, Bristol (location marked B in Fig. 7) showed a 2 degC drop in temperature between 0755 and 0815 UTC. This is evidence of the formation of a cold pool due to rain-cooled convective downdraughts. Since the first rain from Arc 1 was not detected until 0815 UTC, it is likely that the cold pool detected at Bristol was due to the primary storm. Thus Fig. 7 suggests that Arc 1 was initiated at the outflow boundary (gust front) from the primary storm. 


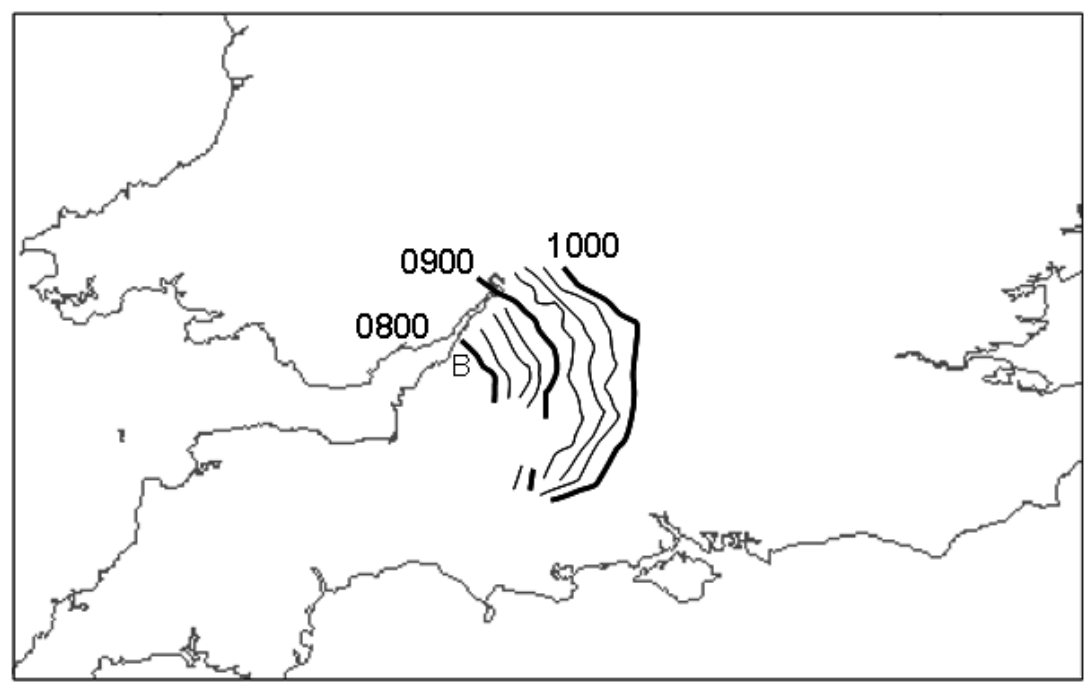

Figure 7. Succession of tracings of the axis of the Arc 1 cloud, shown at 15-minute intervals between 0800 and 1000 UTC. The overall area is the same as in Fig. 3. B marks the location of Filton, Bristol.

New cells also formed ahead of Arc 1 after 0845 UTC. The weather radar network shows that the precipitation from some of these initiated about $40 \mathrm{~km}$ east of Arc 1, from 0915 to 0945 UTC (Fig. 5(d)), and precipitation from another group of cells formed between 60 and $80 \mathrm{~km}$ east and north-east of Arc 1 from 1000 to 1015 UTC. These new cells formed parallel bands of convective showers which will be referred to as Arc 2 and Arc 3, respectively. Arc 2 shows up clearly in the cloud imagery for 0945 in Fig. 6(b). A more ragged array of clouds can be seen ahead of it and these clouds went on to become organized as Arc 3. The radar picture for 0945 UTC (Fig. 5(d)) shows that, although some of the clouds in Arc 2 had begun to precipitate at that time, there was no precipitation yet from any of the clouds in Arc 3. By 1130 UTC (Fig. 5(e)), there is precipitation along much of Arc 3. All these arcs were quite intense at this time, with rainfall intensity in some of the cells exceeding $32 \mathrm{~mm} \mathrm{~h}^{-1}$.

The initiation of Arcs 1,2 and 3 in space and time with respect to the primary storm will now be investigated using distance-time $(x-t)$ plots, or Hovmüller diagrams, derived from the radar network (Fig. 8) and satellite imagery (Fig. 9). The diagrams have been constructed such that the $x$-axis is parallel to the path of the primary storm moving eastsouth-eastwards from south Wales, and then across the Bristol Channel towards Bristol. Rather than describing the properties of the arcs along a single line, we have chosen to plot peak values of these properties within a $30 \mathrm{~km}$ wide swath. This overcomes the problem of individual clouds within the arc having directions of travel that deviate by up to $20^{\circ}$ northwards from the orientation of the $x$-axis. The location of the elongated swath is illustrated in Fig. 5(f). The swath captures the location of the primary storm from birth to decay, as well as the initiation of cells forming Arcs 1, 2 and 3, and the subsequent evolution of these arcs to their mature stage. The swath is sufficiently wide that any newly appearing cells actually formed within it rather than getting advected into it; as shown in Fig. 5(f), the swath also covers Chilbolton (C), Faccombe (F) and Ashmansworth (A), the sites of the clear-air radar, AWS and wind profiler, respectively. Smoothing was used to avoid steps in the Hovmüller plots due to the 15-minute interval between images. The interpolation was carried out along the direction in the Hovmüller 


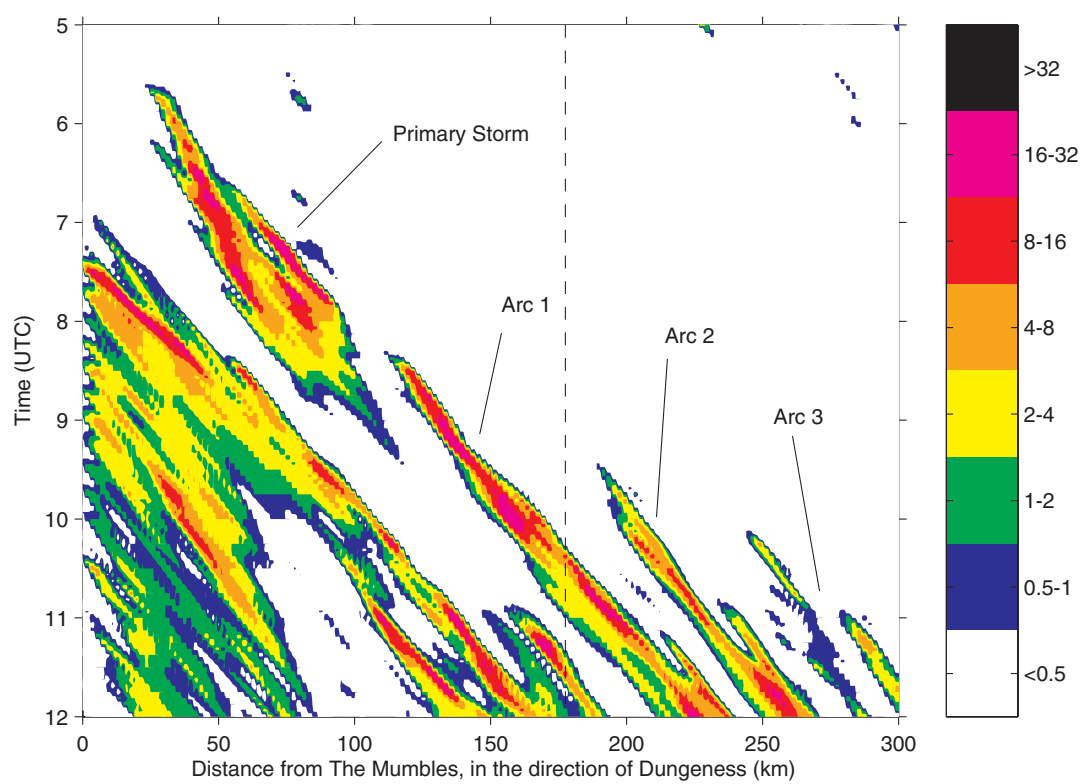

Figure 8. Hovmüller diagram of rain-rate (colour shading, $\mathrm{mm} \mathrm{h}^{-1}$ ). The orientation of the $x$-axis is shown in Fig. 5(f). The dashed line shows the location of Chilbolton. Ashmansworth is $2 \mathrm{~km}$ further east.
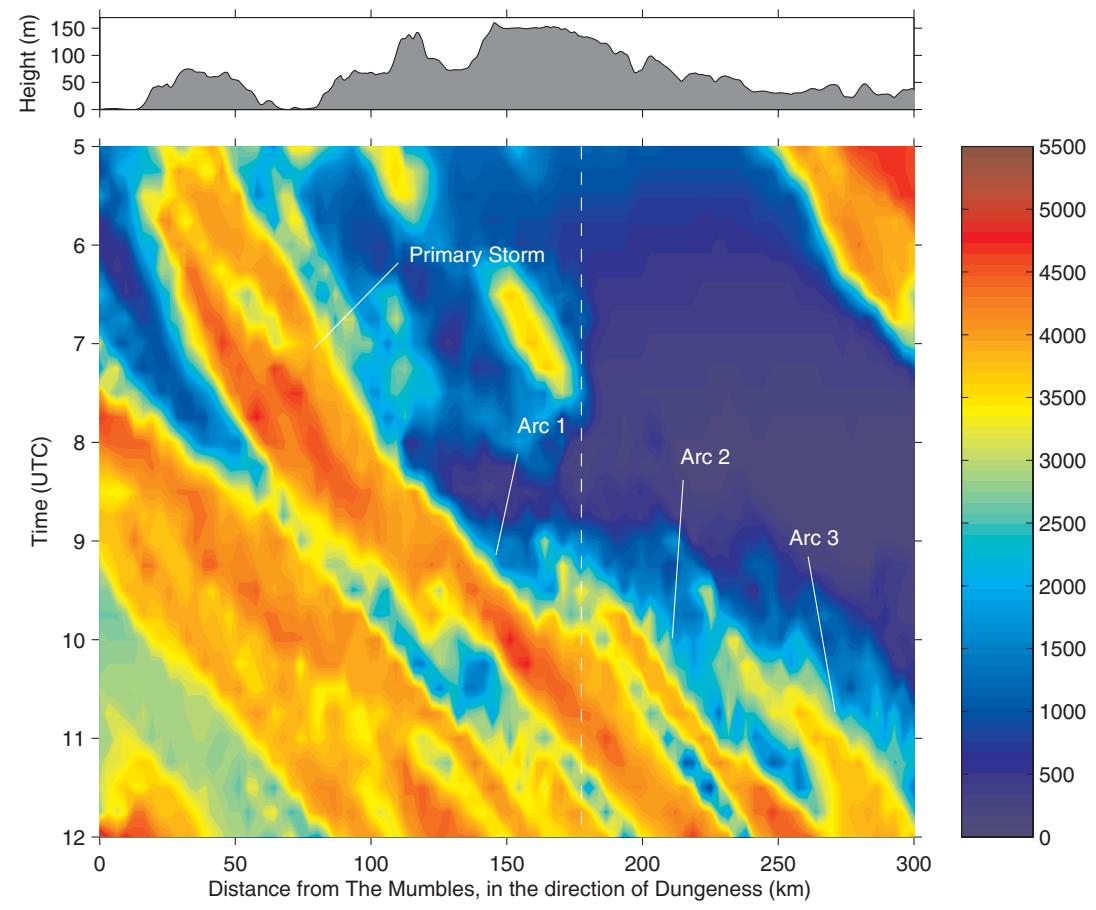

Figure 9. Hovmüller diagram of cloud-top height ( $\mathrm{m}$ above $\mathrm{msl}$ ) inferred from the MSG infrared imagery. The orientation of the $x$-axis is shown in Fig. 5(f), and the dashed line shows the location of Chilbolton. Ashmansworth is $2 \mathrm{~km}$ further east. The height of the terrain averaged over the width of the Hovmüller swath is plotted at the top. 
diagram that corresponds to the speed of travel of Arc 1 . This speed is fairly close to the speed of the other features as well. The smoothing was essentially cosmetic and did not alter the basic structure of the plots.

Figure 8 shows that the primary storm moved at $6.7 \mathrm{~m} \mathrm{~s}^{-1}$ and Arcs 1,2 and 3 at 8.6, 8.3 and $7.8 \mathrm{~m} \mathrm{~s}^{-1}$, respectively. The velocities derived from the Hovmüller diagram relate to the envelope of shower cells making up that precipitation feature. Generally the cells were travelling slower than the envelopes and with a more northward component. Individual cells within the primary storm, and within Arcs 1, 2 and 3 typically travelled at 5.8, 8.1, 7.8 and $6.9 \mathrm{~m} \mathrm{~s}^{-1}$, respectively. The initiation of precipitation in the primary storm and in Arcs 1, 2 and 3 can be seen in Fig. 8 to have occurred at 0530, 0815, 0930 and 1000 UTC, respectively, as previously discussed. Arcs 1, 2 and 3 formed at distances of 90,160 and $220 \mathrm{~km}$ east of the location of the initiation of the primary storm.

The cloud-top-height Hovmüller diagram in Fig. 9 has been derived from the MSG infrared imagery using model-derived soundings to convert cloud-top temperatures to approximate heights. To allow for parallax errors, the imagery was also renavigated by matching the brightest clouds in the visible imagery to the most intense echoes in the radar imagery. The relationship between cloud and rain features in Figs. 8 and 9 is shown in detail later in section 3(c). However, for the moment we restrict ourselves to noting that, although the high cloud tops in Fig. 9 broadly correspond to the arc rain bands in Fig. 8, the associated region of deeper cloud can be traced back further in time because of the time taken for radar-detectable precipitation to develop. In the case of the betterdefined Arc 2, cloud tops of at least $2 \mathrm{~km}$, corresponding to the $0^{\circ} \mathrm{C}$ level, preceded the radar-detectable precipitation by about half an hour. A straight line can be drawn through the initiation points of Arcs 1,2 and 3 in Fig. 8. This line has a phase speed of $20 \mathrm{~m} \mathrm{~s}^{-1}$. However, a similar line cannot be drawn through the cloud-top height data in Fig. 9, as clouds associated with Arc 3 formed within 15 minutes of those associated with Arc 2.

To understand the mechanisms that led to the initiation of the precipitation arcs, we actually need to investigate the atmospheric behaviour at the earlier time and place of the formation of the cloud structures associated with them. The Arc 1 clouds formed ahead of the primary storm and Arcs 2 and 3 formed ahead of both the primary storm and Arc 1. Possible mechanisms by which the arc formation may have been influenced by the primary storm, or by a preceding arc, include gust fronts (density currents), gravity waves and undular bores. We investigate the occurrence of a gust front next, in section 3(c) and then examine evidence for a wave-like perturbation to the boundarylayer depth which may have been due to gravity waves in section 3(e). The interaction of a density current with a two-layer stably stratified flow, to form an undular bore such as the one described by Smith et al. (1982), is unlikely due to the presence of a neutral boundary layer (Fig. 4). The precise time of initiation of convection, and indeed the slight scatter in the location of the initiation of individual cells, causing departures from perfectly smooth arc rainbands, may have been influenced by local topography. The average height of the terrain within the Hovmüller swath is plotted in the panel at the top of Fig. 9. There is a hint of topographic influence insofar as the clouds associated with the primary storm and Arcs 1 and 2 form close to regions of more elevated terrain; however, this is less clear in the case of Arc 3. To obtain a more reliable assessment of orographic influence, it is necessary to examine a sample of cells initiating over a larger area and this is done in section 3(f). There is evidence in Fig. 9 of short-lived patches of non-precipitating cloud long before the rain showers developed in Arc 3. These can be seen at around 0500 and $0700 \mathrm{UTC}$, at a location approximately in line with where Arc 3 would be expected to have been, assuming a constant phase speed. These cloud patches 

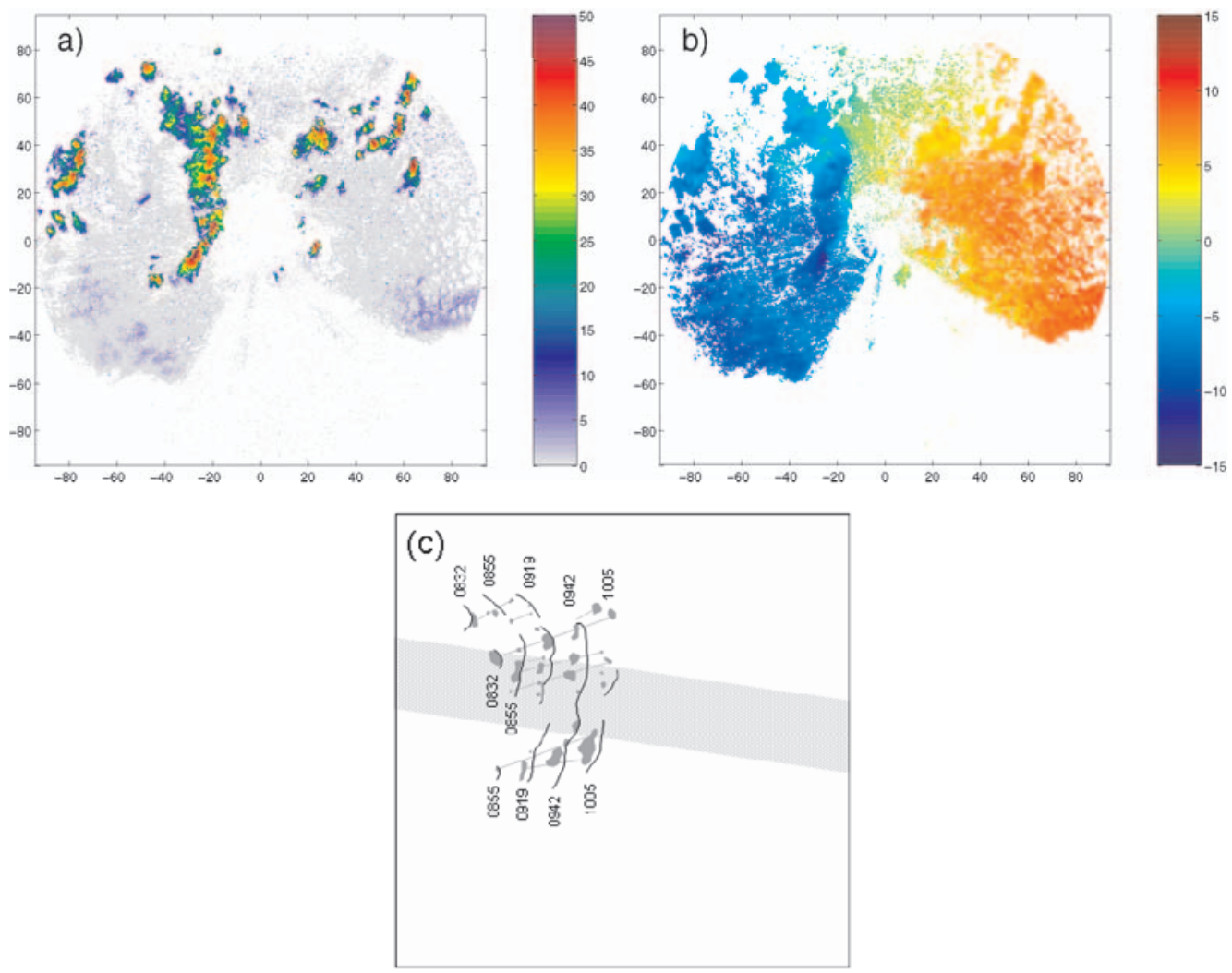

Figure 10. Data from the rain radar at Chilbolton (location shown by ' $\mathrm{C}$ ' in Fig. 5(f)): PPIs at $0.5^{\circ}$ elevation of (a) reflectivity (dBZ) and (b) Doppler velocity away from the radar $\left(\mathrm{m} \mathrm{s}^{-1}\right)$ at $0942 \mathrm{UTC}$; (c) the Arc 1 gust front and rain cells at a series of times, plotted over the same area as panels (a) and (b). Precipitation echoes with reflectivity greater then $30 \mathrm{dBZ}$ are shaded dark grey, while the location of gust fronts as shown by Doppler PPIs are indicated by black lines. The data were collected during 5 PPIs at 0832, 0855, 0919, 0942 and 1005 UTC. Light grey lines show interpolated trajectories for individual cells. A portion of the swath used in calculating the Hovmüller diagrams is shaded light grey. The data-sparse quadrant to the south in (a) and (b) is due to blockage of the beam.

are not believed to be related to Arc 3; their motion was slower than Arc 3 (5.6 m s${ }^{-1}$ compared with $7.8 \mathrm{~m} \mathrm{~s}^{-1}$ ) and their direction of travel had a more northerly component.

\section{(c) Behaviour of the gust front associated with Arc 1}

We presented evidence in section 3(b) which suggested that Arc 1 was triggered at the leading edge of the gust front (density current) due to the primary storm. Arc 1 also produced a gust front, which was tracked by Doppler radar, and in this section we investigate whether or not Arc 2, which formed ahead of Arc 1, could have been triggered by the Arc 1 gust front. Another issue is whether Arc 3 could have been triggered in turn by a gust front from Arc 2. This, however, can be ruled out since the first clouds associated with Arc 3 were triggered within 15 minutes of the first cloud forming Arc 2 and prior to any precipitation developing in Arc 2.

Figure 10 shows a plan position indicator (PPI) of reflectivity and Doppler velocity from the rain radar at 0942 UTC. The dominant north-south line of echoes to the northwest of the radar in Fig. 10(a) corresponds to Arc 1. The linear depolarization ratio (Ldr) has been used to differentiate high reflectivities due to rain from those due to 


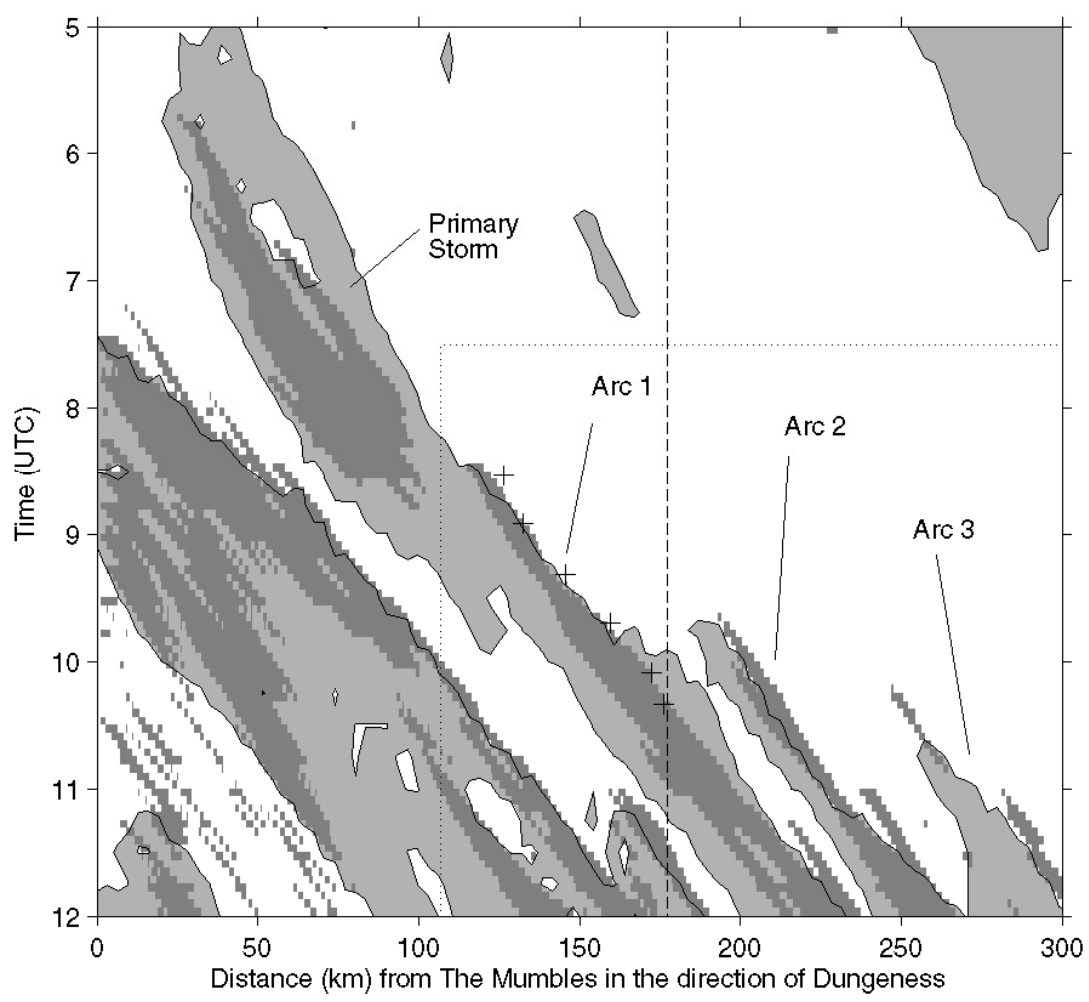

Figure 11. Composite Hovmüller diagram showing observations of Arc 1's gust front (crosses) superimposed on the rainfall and cloud distributions. Rain-rates $>2 \mathrm{~mm} \mathrm{~h}^{-1}$ are shaded dark grey and cloud tops $>3.5 \mathrm{~km}$ are shaded light grey. The dotted line indicates the region shown in more detail in Fig. 18, and the vertical dashed line shows the location of Chilbolton.

ground clutter at close range (Wilson et al. 1995); reflectivities whose associated Ldr is greater than $-20 \mathrm{~dB}$ have been removed. An arc-shaped feature of abrupt changes in horizontal wind (Fig. 10(b)), corresponding to an arc of radial confluence, is located just ahead of the cells making up Arc 1 (Fig. 10(a)). This is Arc 1's gust front.

The locations of the arc of confluence at a series of times has been determined from Doppler data similar to Fig. 10(b), obtained from 0832 to 1005 UTC; the results are summarized in Fig. 10(c). These locations are also plotted as a series of crosses on a composite Hovmuiller diagram in Fig. 11. Additionally, Fig. 12 shows that a gust front was detected at 1020 UTC by the AWS at Faccombe (see Fig. 5(f) for location) as a $4 \operatorname{degC}$ drop in temperature, a peak gust of $9 \mathrm{~m} \mathrm{~s}^{-1}$, a wind veer and a small pressure rise. This observation has also been plotted in Fig. 11. Also shown in Fig. 11 is a simplified portrayal of the combined cloud and rainfall information taken from Figs. 9 and 8. The gust-front observations line up along the leading edge of the rainfall associated with Arc 1, and the speed of the gust front is seen to be the same as that of the cloud tops and precipitation in that arc. If the line joining the gust-front observations is extended backwards in time, it ends up close to the leading edge of the primary storm, consistent with the earlier finding that Arc 1 was triggered by the gust front from the primary storm. On the other hand, Arc 2 formed not on but rather $40 \mathrm{~km}$ ahead of Arc 1's gust front. Similarly, as noted above, Arc 3's cloud formed ahead of Arc 2 at about the time that 

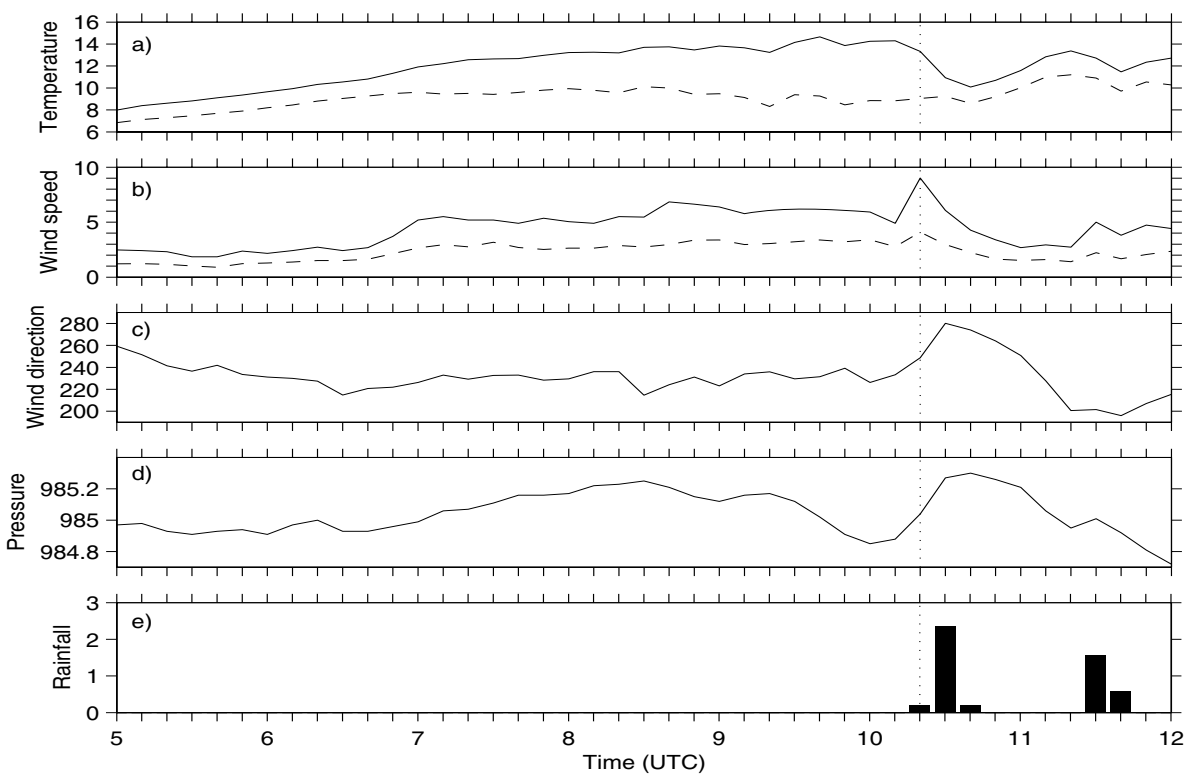

Figure 12. Surface measurements made by the automatic weather station at Faccombe (location shown by 'F' in Fig. 5(f)): (a) temperature (solid) and dew point (dashed), both ${ }^{\circ} \mathrm{C}$, (b) mean wind speed (dashed) and maximum wind speed (solid), both $\mathrm{m} \mathrm{s}^{-1}$, (c) wind direction (degrees clockwise from north), (d) surface pressure (hPa), and (e) total rainfall $(\mathrm{mm})$. The data shown are the means for each 10 minutes (or maximum in the case of the maximum wind speed). The vertical dotted line draws attention to the time of the passage of Arc 1's gust front.

Arc 2's cloud was forming, i.e. before Arc 2 could have developed a gust front. Thus, unlike Arc 1, neither Arc 2 nor Arc 3 could have been initiated at the leading edge of a pre-existing gust front.

\section{(d) Evolution of the vertical structure during initiation of Arc 2}

Figure 13 shows the MSG visible cloud and radar rain rate at 15-minute intervals from 0900 to $0945 \mathrm{UTC}$, around the time when Arc 2 was forming to the east of the mature Arc 1. The locations of the wind-profiler (A) and Chilbolton radars (C) are also shown for reference. It can be seen that Arc 2 formed close to the wind profiler and within range of the clear-air radar. These radars, as we shall show, provided valuable observations of the vertical structure of the atmosphere in the vicinity of Arc 2 before, during, and after the initiation of Arc 2. Eight convective cells formed within Arc 2 during this period and they are labelled in Fig. 13 as 1 to 8. We later illustrate the initial development of some of these cells (3, 4, 6 and 8), but first we examine the evolution of the overall vertical structure of the atmosphere in their vicinity as observed by the wind-profiling radar at Ashmansworth.

Figure 14 shows a time-height plot of signal strength from the wind profiler. The radar was operating all day but here we concentrate on the data from 0600 to 1200 UTC. The data show that there was a set of echo layers. Most of these are highly laminar, an indication of the highly stratified nature of much of the atmosphere. However, the lowermost echo, associated with the boundary layer and convection, is more irregular and more intense. To simplify the discussion of these echoes we sketch them in Fig. 15.

Like the stratified layers above the boundary layer, the intense echo at low levels was mostly due to refractive index inhomogeneities. The higher intensity of the echoes in the 

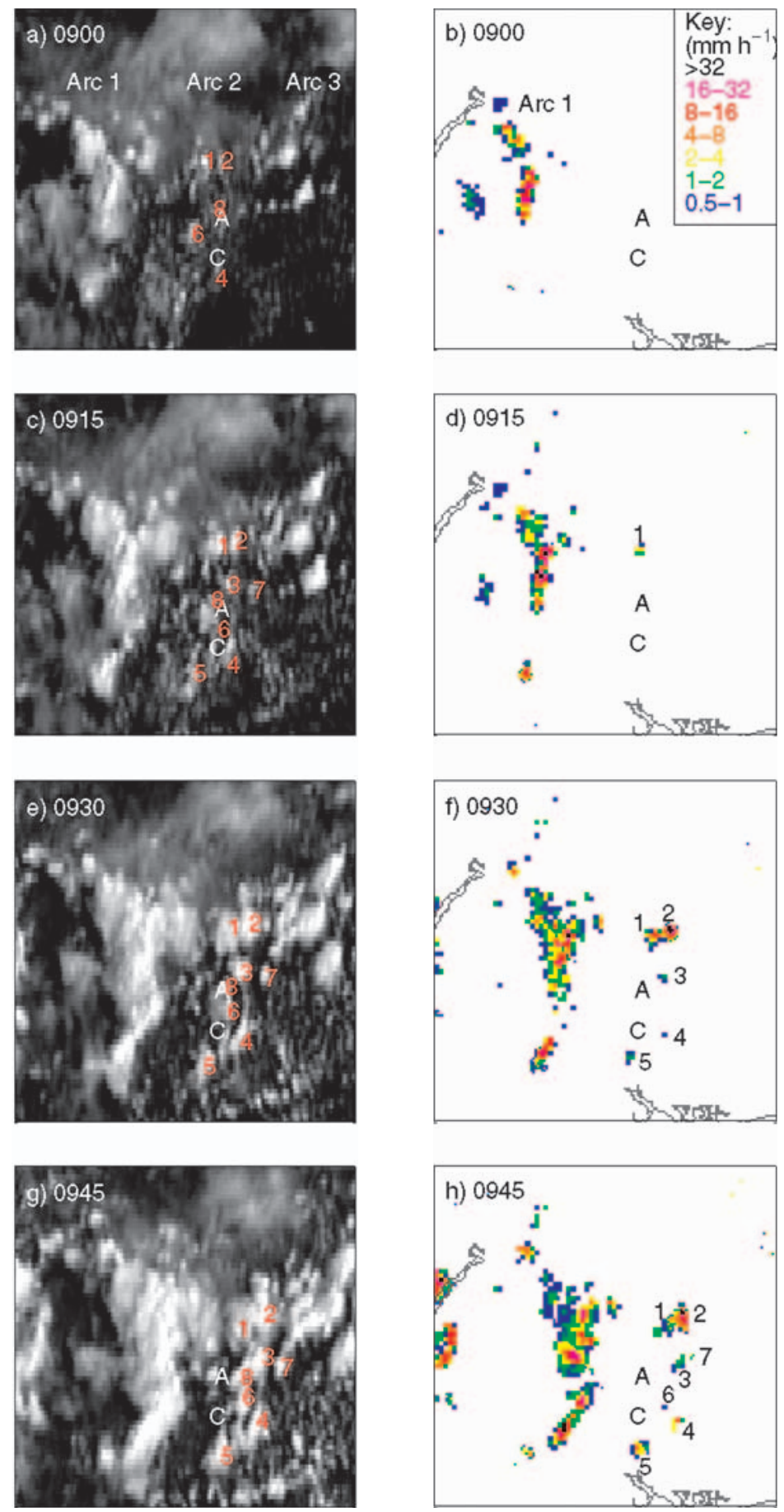

Figure 13. MSG high-resolution visible satellite imagery (left) and radar-network rain-rate (right), within a $150 \mathrm{~km} \times 150 \mathrm{~km}$ area, at (a, b) 0900, (c, d) 0915, (e, f) 0930 and (g, h) $0945 \mathrm{UTC}$, during the formation of Arc 2. The subregion corresponds to that in Fig. 5(d), whose location is shown in Fig. 5(f). Individual cloud cells are labelled in both sets of images, to draw attention to the developing clouds and showers within Arc 2 . Arc 1 is already well developed and precipitating $40 \mathrm{~km}$ to the west of Arc 2, while clouds associated with Arc 3 are forming $40 \mathrm{~km}$ to the east, although no precipitation was detected from these until after $1000 \mathrm{UTC}$. The locations of the wind profiler at Ashmansworth (A) and the clear-air radar at Chilbolton (C) are indicated. 


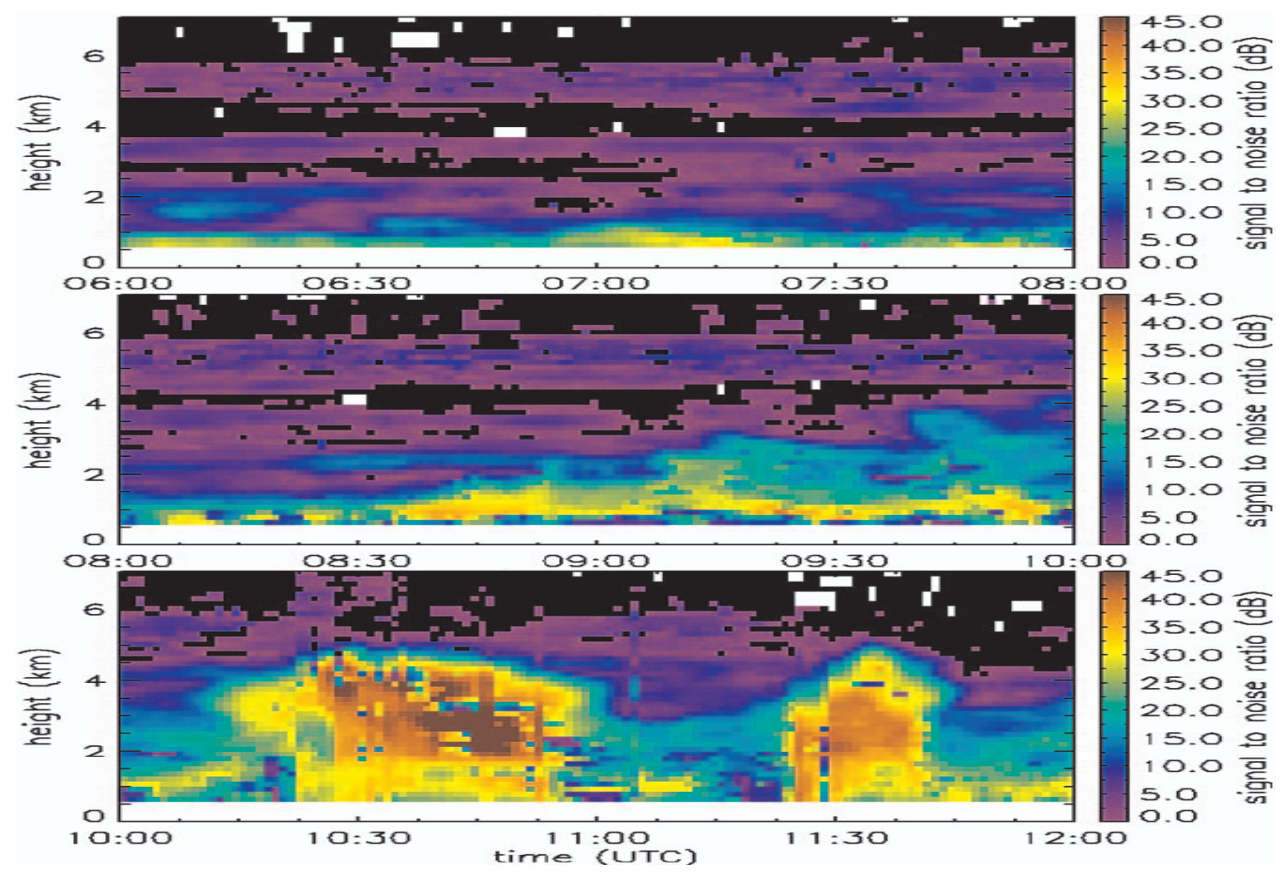

Figure 14. Time-height record of signal strength (dBZ) from the wind-profiler radar at Ashmansworth (location shown by 'A' in Figs. 1 and 5(f)) for the period between 0600 and 1200 UTC, based on 1-minute averages. The colours indicate minimum signal-to-noise ratio from the three beams.

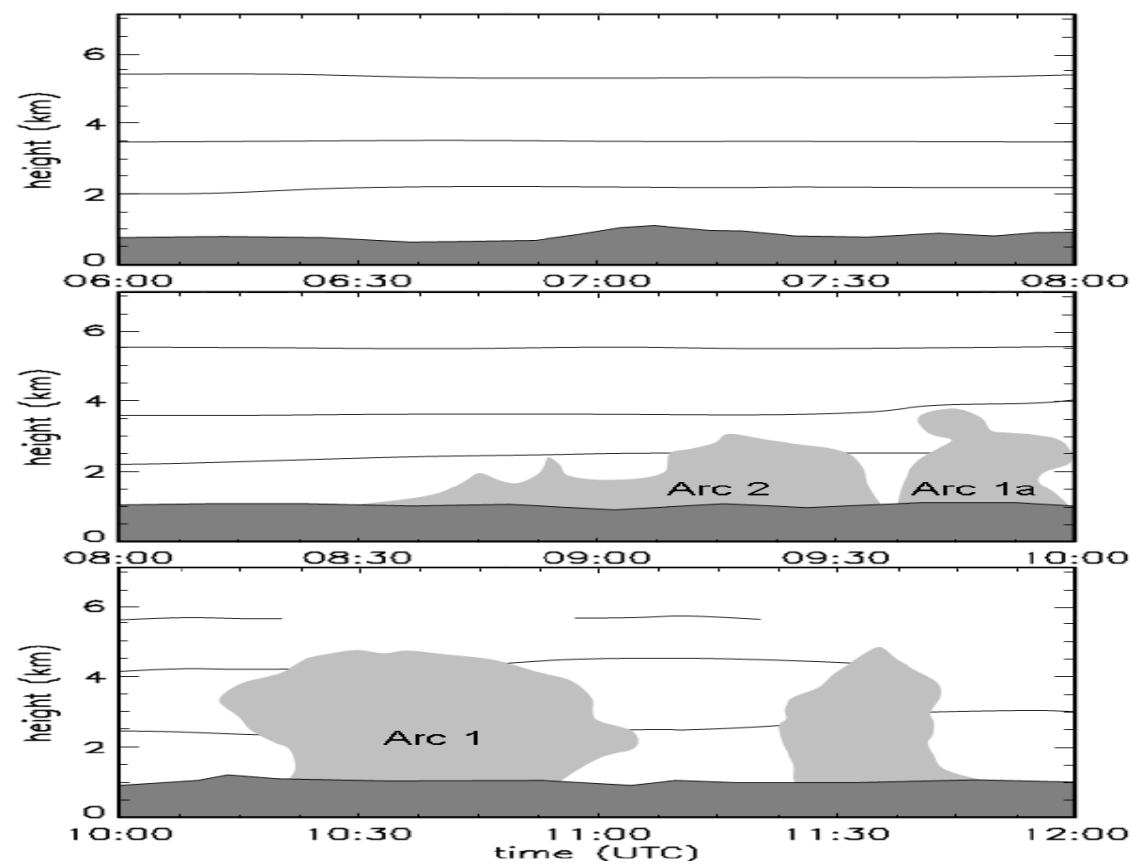

Figure 15. Analysis of echoes seen in the wind-profiler data for the period between 0600 and 1200 UTC. The black lines indicate the layers subjectively identified from Fig. 14. The dark grey shading denotes the more intense echo associated with boundary-layer air and the light grey shading denotes intense echo due to the more vigorous convection that extended to levels above the boundary layer. 
region with hatched shading in Fig. 15 is, for the most part, an indication of boundarylayer air with a high degree of refractive index inhomogeneity. This inhomogeneity can be expected to be greatest at the top of the boundary layer where the boundary-layer turbulence and the tops of thermals encounter the capping stable layer leading to mixing between the humid boundary-layer air and the drier air above; however this was not easily resolved by the wind-profiler data. The vertical (range) resolution of the wind profiler, as operated on 10 July, was $143 \mathrm{~m}$, whilst its effective horizontal resolution, bearing in mind that it uses two off-vertical beams at differing azimuths, was around $1200 \mathrm{~m}$ at an altitude of $2 \mathrm{~km}$. Nevertheless, the height of the maximum echo intensity at 0900 UTC in Fig. 14 (at the top of the hatched layer in Fig. 15) is broadly consistent with the 0900 UTC model sounding for Larkhill in Fig. 4(b) (Larkhill is $33 \mathrm{~km}$ from the wind profiler, see Fig. 1) which shows the base of the overlying stable layer at around $920 \mathrm{hPa}(800 \mathrm{~m})$. Early in the period shown in this figure (before about $0830 \mathrm{UTC}$ ), the boundary layer is seen to be shallower, but its depth cannot be diagnosed reliably from the wind-profiler data because the top of the boundary layer was then within the layer where the sensitivity of this radar was falling off rapidly with decreasing height. Evidence presented later (section 3(e)) suggests that the top of the boundary layer varied between 500 and $800 \mathrm{~m}$ at 0800 UTC.

After about 0830 UTC, Fig. 14 shows that the region of low-level echo began penetrating upwards above the intense echo attributed to the boundary layer so as to produce the non-laminar regions of echo that are identified by lighter shading in Fig. 15. Range-height indicator (RHI) scans from the clear-air radar, to be presented shortly, show that the shaded regions were associated with convective thermals. As identified in Fig. 15, the first region of convection encountered by the wind profiler was Arc 2. A further minor region of convection passed overhead just after 0945 UTC. This was associated with a small line of convective cells, not previously referred to, which we shall call Arc 1a, which developed between Arcs 1 and 2. The convection associated with Arc 2 which began to develop after 0830 UTC appears to have penetrated a stratified layer at $2.7 \mathrm{~km}$ around the time (between 0915 and 0930) when Fig. 13 shows that a nonprecipitating cloud within the developing Arc 2 was passing overhead. This is labelled cloud cell 8 in Fig. 13. Between 1020 and 1055 UTC, a region of deeper convection passed overhead, with tops to almost $5 \mathrm{~km}$, which appears from Figs. 14 and 15 to have penetrated above a further stratified echo layer. This convection was associated with the mature Arc 1 . Arc 1 at this time was producing heavy precipitation and this contributed to the observed enhancement in echo intensity (see the brown echo from 1015 and 1050 UTC which corresponds to the passage of the Arc 1 showers). Later we refer to this as Type 2 echo to distinguish it from so-called Type 1 Bragg echoes.

The increasing height to which convection from the surface can penetrate is probably due to the continuing surface heating associated with the diurnal cycle. However, the specific moment and location at which a stable layer, or lid, is breached may be determined by additional effects as discussed later.

In order to clarify our interpretation of Fig. 14 in terms of convection penetrating the top of the boundary layer, we look next at RHI data from the Chilbolton clearair radar (Fig. 16). On 10 July 2004, the scanning procedure used for the Chilbolton radars consisted of ten RHIs, from 0 to $15^{\circ}$ in elevation, roughly $36^{\circ}$ apart in azimuth, followed by a $360^{\circ} \mathrm{PPI}$ at $0.5^{\circ}$ elevation. In order to improve the detection of weak clear-air echoes, the radar dish scans only slowly, at $1^{\circ} \mathrm{s}^{-1}$ in azimuth and $0.25^{\circ} \mathrm{s}^{-1}$ in elevation, so the whole scan cycle takes around 23.3 minutes. This scan cycle was repeated continuously throughout the day. The number of RHIs in each cycle was limited to ten in order to reduce the length of the cycle; however, this led to widely spaced RHIs 

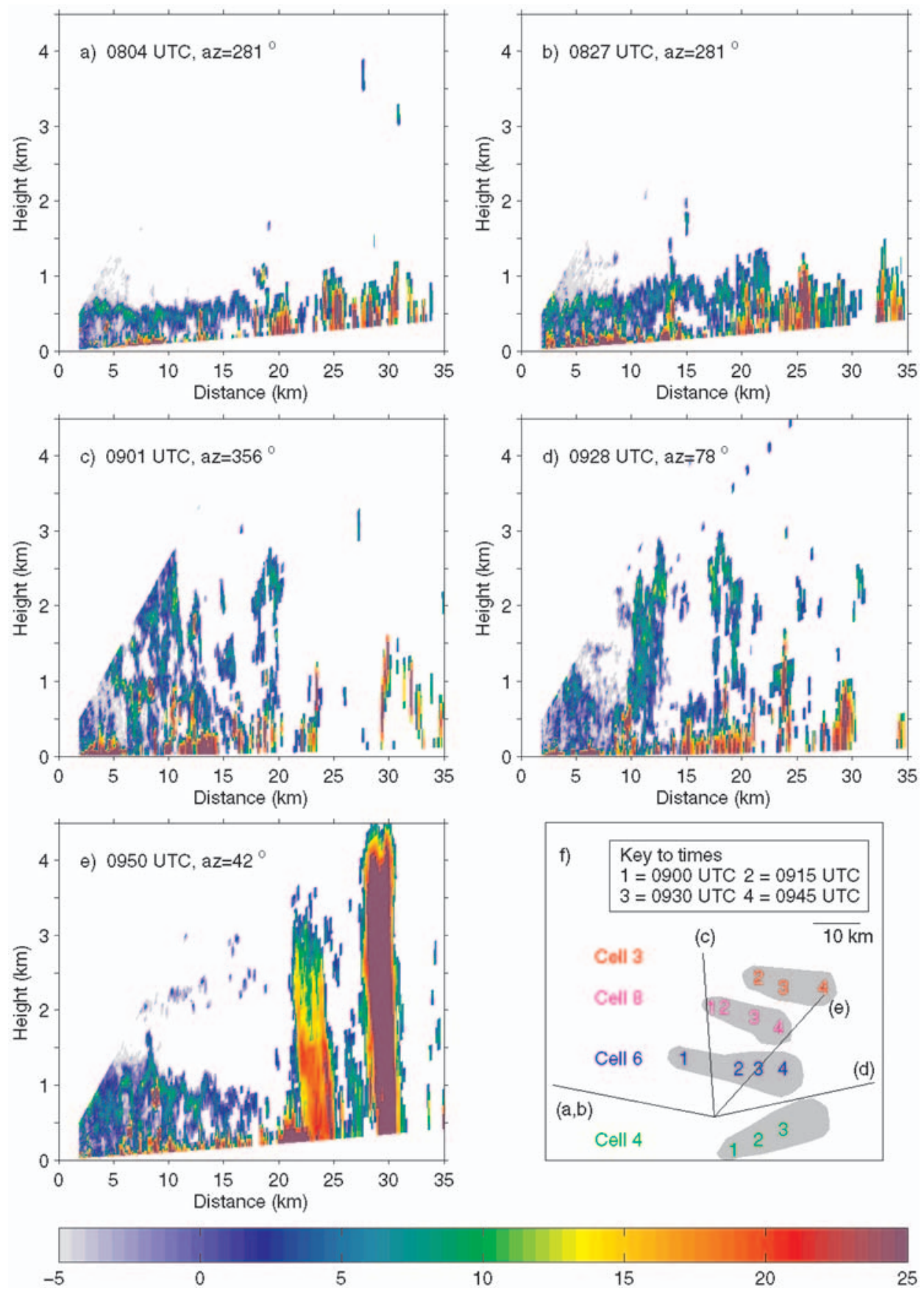

Figure 16. Clear-air radar reflectivity RHIs (colour shading, dBZ), showing the development of convective elements that go on to form Arc 2: (a) weakly perturbed boundary layer, with thermals rising to between 500 and $600 \mathrm{~m}$, (b) more perturbed boundary layer, with thermals rising to between 600 and $900 \mathrm{~m}$, (c) cloud cell 6, at $10 \mathrm{~km}$ range, and cell 8 , at $19 \mathrm{~km}$ range, rising to $2.6 \mathrm{~km}$ up to 15 minutes before they are obvious in Fig. 13(c), (d) cloud cell 4 and cloud cell 6 up to $3 \mathrm{~km}$, and (e) cloud cells 8 and 3 at ranges of 23 and $30 \mathrm{~km}$, respectively, about 30 minutes after first detected by satellite (cloud cell 3 is seen about 20 minutes after first radar network echoes; cloud cell 8 has just reached the first precipitation echo stage). (f) is a schematic showing the tracks of cloud cells 3, 4, 6 and 8 (digits and shading) at 0900, 0915, 0930 and 0945 UTC. Corresponding satellite images are shown in Fig. 13. The orientations of the RHI scans used in (a) to (e) are also shown. 
which provide only a partial sample of the developing convection. The five RHIs shown in Fig. 16 have been selected to characterize the early development of the convective cells within Arc 2. We shall interpret the detail in these RHIs shortly in terms of specific atmospheric features. First, however, we need to describe in broad terms the four generic kinds of echo portrayed in these RHIs:

Type 1: Weak echoes (generally blue or green in Fig. 16, i.e. 0 to $12 \mathrm{dBZ}$ ) forming envelopes either around individual convective cells, or at the top of the boundary layer, due, as explained earlier, to Bragg scattering from inhomogeneities in the refractive index (mainly due to variations in relative humidity) at these boundaries. In most cases the convective cells are cloudy rather than clear air, but at L-band almost all of the signal in a non-precipitating cloud is from the refractive index inhomogeneities rather than from cloud droplets.

Type 2: More extensive echoes within convective cells (ranging from yellow to purple, i.e. $12 \mathrm{dBZ}$ and above) due to Rayleigh scattering from precipitation particles. These echoes range from weak to strong according to the size of the particles. The Type 2 echoes will exist within an envelope of Type 1 echo but the Type 2 echoes will dominate over the latter.

Type 3: Small discrete echoes in the lowest $1 \mathrm{~km}$ (yellow to purple) due perhaps to Rayleigh scattering from large insects or, more likely, Mie scattering from individual birds. Fortunately, these are distinct and easily distinguished visually from the other types of echo which are the subject of the ensuing analysis.

Type 4: Discrete echoes (yellow to purple) extending from the surface up to about $0.5 \mathrm{~km}$ in places due to side-lobe returns from ground targets.

The wind profiler was sited at Ashmansworth, $19 \mathrm{~km}$ north of Chilbolton (see Figs. 1 and 13), so that RHI scans could be performed that were capable of providing clear-air echoes above and in the close vicinity of the wind profiler. The locations of the RHI scans are plotted in Fig. 16(f) together with tracks of four convective clouds (derived from Fig. 13) that are portrayed in Figs. 16(c), (d) and (e).

The first RHI, at 0804 UTC (Fig. 16(a)), obtained over an hour before the initiation of Arc 2, shows a fairly smooth Type 1 echo layer between 500 and $600 \mathrm{~m}$ out to $19 \mathrm{~km}$ (echoes beyond this range are mainly Type 3), suggesting that the top of the boundary layer was not yet being strongly perturbed by boundary-layer convection. By 0827 UTC, Fig. 16(b) shows that the boundary layer where Arc 2 was about to develop had deepened to between 600 and $900 \mathrm{~m}$, and its top was being strongly distorted by convective circulations within the boundary layer. None of these convective elements, however, was penetrating significantly above the capping stable layer at this time.

A pronounced change in the appearance of the Type 1 echoes began to occur after about 0850 UTC. Convective clouds had penetrated through the lid by 0901 UTC and were rising buoyantly (Fig. 16(c)). Figure 16(f) shows that the convective element in Fig. 16(c) at a range of $19 \mathrm{~km}$ from Chilbolton was from cloudy convection associated with cell 8 which also showed in the satellite visible imagery at 0900 UTC (Fig. 13(a)). Figure 16(f) shows that the edge of cell 6 (or an adjacent cell) was also detected in the scan shown in Fig. 16(c). Cloud would be associated with the convection within these boundaries but the Rayleigh scatter from the small cloud particles at this stage will have been too weak to be detected.

Subsequently cells 6 and 8 drifted eastwards at about $8.1 \mathrm{~m} \mathrm{~s}^{-1}$. The southern edge of cell 6 was detected up to a height of 2 to $3 \mathrm{~km}$ at ranges between 10 and $13 \mathrm{~km}$ in the RHI scan towards $078^{\circ}$ (Fig. 16(d)). This scan, made at 0928 UTC, was 28 minutes after the satellite imagery first showed a clear signature for this cell in the visible channel. 
At the same time, the scan in Fig. 16(d) shows another convective cell reaching a height of 2 to $3 \mathrm{~km}$ at ranges between 17 and $20 \mathrm{~km}$. This was associated with the northern edge of cell 4 (or an adjacent cell) which was first detected in the visible imagery just south of Chilbolton at 0900 UTC.

Meanwhile, a little farther north, cells 3 and 8 had developed vigorously as they drifted eastwards. Figure 16(f) shows that by 0945 UTC they were within the RHI section along $042^{\circ}$ scanned by the clear-air radar at 0950 UTC (Fig. 16(e)). Figure 16(e) shows Type 1 echoes from a convectively perturbed boundary-layer top varying in height from 700 to $1500 \mathrm{~m}$ out to a range of $20 \mathrm{~km}$, with no convection penetrating significantly above the boundary layer, but beyond $20 \mathrm{~km}$ there were two cells of penetrative convection both of which were producing Type 2 echo. The intense echo rising above $4 \mathrm{~km}$ near $30 \mathrm{~km}$ range is from cell 3 . Its reflectivity exceeds $45 \mathrm{dBZ}$ in places and there is evidently heavy precipitation. The radar-network pictures in Fig. 13 suggest that cell 3 had begun raining already by 0930 UTC but that, probably because of the averaging of reflectivity over $5 \mathrm{~km}$ in this region, it still appeared to be producing rainfall rates of only about $1 \mathrm{~mm} \mathrm{~h}^{-1}$ at $0945 \mathrm{UTC}$. The other echo rising above $3 \mathrm{~km}$, between 22 and $25 \mathrm{~km}$ range in Fig. 16(e), is from cell 8 which, although it was first detected by the clear-air Chilbolton radar at 0901 UTC (Fig. 16(c)) and in the visible imagery at 0915 UTC (Fig. 13(c)), was producing a rainfall rate less than $0.5 \mathrm{~mm} \mathrm{~h}^{-1}$ at 0945 UTC and hence does not appear in Fig. 13(h), where signal below $0.5 \mathrm{~mm} \mathrm{~h}^{-1}$ has not been plotted (to avoid confusion caused by ground clutter). However, the fact that Fig. 16(e) shows that the interior of this convective cell was filled in by Type 2 echo suggests that precipitation was beginning to develop extensively within it at 0950 UTC.

\section{(e) Systematic spatial variations in the depth of the boundary layer during the initiation of Arc 2}

We have seen from Fig. 16 that the RHIs from the clear-air radar show both the depth of the boundary layer and the tops and edges of the convective clouds that penetrate above the boundary layer. We now concentrate on the former and use a series of sets of ten RHIs at different azimuths made every 23.3 minutes to analyse the spatial variability in the boundary-layer depth. In order to quantify the variations in boundary-layer top seen in the clear-air RHIs, the height of the lowest detected layer has been measured subjectively. Layers occasionally detected higher up and which are clearly not related to the boundary layer have been ignored. The height of the boundary-layer top has been measured every $2.5 \mathrm{~km}$ along each RHI radial. An actual mean value has not been used; instead we have used a subjectively inferred height, to the nearest $50 \mathrm{~m}$, that neglects the local lifting of the boundary-layer top by individual convective thermals.

These estimates of boundary-layer top were made at radar ranges between 5 and $30 \mathrm{~km}$, for all the available azimuths and for all the scan cycles. The height of the boundary layer along each azimuth was then plotted in the horizontal plane for each of the scan cycles, an example from one such cycle being shown in Fig. 17. One of the RHIs shown previously (Fig. 16(a)) was in fact used in deriving Fig. 17. It is clear from Fig. 16(a) that it is not possible to discern the boundary-layer top (blue or green echo) at long ranges because of the presence of spurious echoes (yellow to purple) due perhaps to birds. In such cases, Doppler velocity plots were used (not shown) to distinguish the wanted echoes. The analysis technique described by Barnes (1964) was used to interpolate between the irregularly spaced data (see the coloured shading in Fig. 17). There are marked variations from west to east, with higher values (up to $700 \mathrm{~m}$ ) to the west and east separated by lower values (about $400 \mathrm{~m}$ ) in a strip extending roughly north to south through the radar site. A similar trend was evident in the later cycles, albeit with 
the strip of lower boundary-layer tops moving eastwards with time. We interpret this in terms of a weak wave-like perturbation in boundary-layer depth, with the trough almost overhead of the radar site in Fig. 17. To examine the evolution of the wave we have used the series of plots like Fig. 17 to generate a Hovmüller diagram for the swath shown in Fig. 5(f), and also in Fig. 17. This swath was $30 \mathrm{~km}$ wide and its width extended northwards from Chilbolton to beyond the wind-profiler at Ashmansworth. The height of the boundary layer averaged over the width of this swath was calculated as a function of distance along the length of the swath, allowing a Hovmüller diagram of boundarylayer top to be derived for comparison with the earlier Hovmüller diagrams.

Figure 18 shows the resulting Hovmüller diagram; it includes features from the boundary-layer-top analysis (in colour) as well as the thresholds shown in Fig. 11. A ridge of boundary-layer deepening can be seen upstream prior to the formation of the clouds and rain associated with Arc 2. Comparison with Figs. 8 and 9 shows that this boundary-layer deepening began at least 2 hours before the appearance of Arc 2 cloud at the $3.5 \mathrm{~km}$ level and also at least 2 hours before it starts to rain. There is also a hint of another ridge in the boundary-layer depth which lines up with the position of Arc 3 later on, so this ridge may well be evidence of boundary-layer variations prior to the formation of Arc 3. The propagation velocity of the boundary-layer ridge has been constrained to some extent to be similar to that of the cloud and rain associated with Arc 2 because the smoothing was carried out in this direction; nevertheless the velocity of propagation of the boundary-layer ridge associated with Arc 2 appears to be close to that of the clouds and rain associated with Arc 2. There is also evidence of the ridge in the boundary-layer top being present prior to the arc clouds forming. This wave has an amplitude of around $\pm 150 \mathrm{~m}$ at around 0800 UTC (increasing to about $\pm 200 \mathrm{~m}$ by $0900 \mathrm{UTC}$ ), and a wavelength of $40-50 \mathrm{~km}$, while it has a velocity component of $8.1 \mathrm{~m} \mathrm{~s}^{-1}$ within the cross-section. We therefore hypothesize that the wave-like perturbation in boundary-layer depth may have played a role in triggering the arc clouds and that, because the wave travelled at a velocity comparable with that of the resulting convective clouds, they remained roughly in phase, thereby reinforcing their continued development. (If the wave had travelled at a velocity significantly different from that of the convective clouds it could have triggered new convective initiation outside of the initial cloud arcs).

\section{$(f)$ Local topographical effects on the triggering of convection}

The topography of southern Britain is quite gentle, with only a few hills rising above $200 \mathrm{~m}$. Nevertheless this vertical extent is comparable with the amplitude of the wave-like disturbance and the importance of topography cannot be dismissed a priori. Also such hills may have had an effect through differential elevated heating. We noted in section 3(b) that, within the Hovmüller swath, the terrain did not have a clear influence on the location of initiation of the Arcs. However, this constituted too small a sample to enable us to draw any firm conclusions. Therefore, to investigate more thoroughly the extent to which topography may have influenced convective initiation, we have plotted in Fig. 19 the location of first precipitation echoes detected by the weather-radar network (triangles) and the location of the first identifiable cloud feature associated with that precipitation (circles) for all of the showers associated with Arcs 1, 1a, 2 and 3, and we have superimposed these on the terrain height averaged over $1 \mathrm{~km} \times 1 \mathrm{~km}$ regions. The trajectories followed by these convective clouds between their formation and the first detected precipitation are shown by black lines. The influence of topography is not clear-cut. However, at first sight there appears to be a tendency sometimes for the periods of cloud growth between first cloud and first precipitation to coincide with travel 

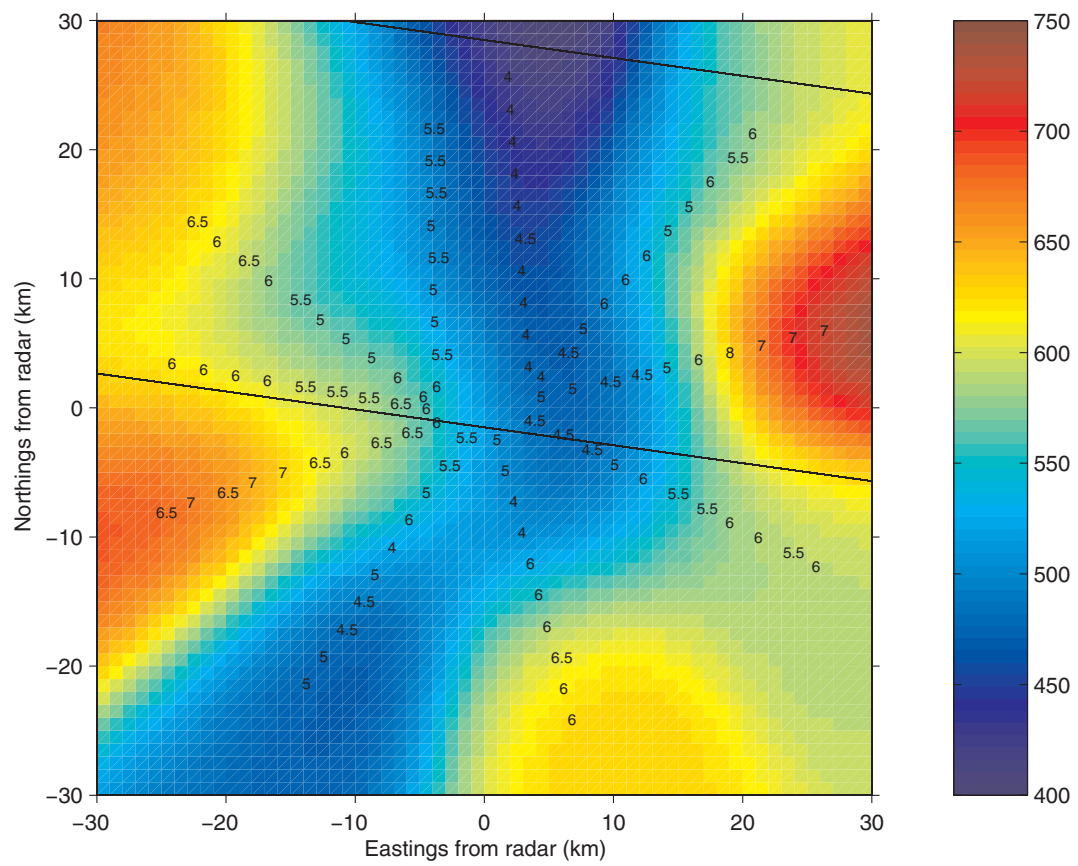

Figure 17. Height of the boundary-layer top (digits, $10^{2} \mathrm{~m}$ ), as derived from ten RHI scans with the Chilbolton clear-air radar. The interpolated heights $(\mathrm{m})$ are given by the colour shading. The scans were obtained from 0751 to 0807 UTC and their positions have been displaced to correspond to 0758 UTC, assuming a westerly system velocity of $8 \mathrm{~m} \mathrm{~s}^{-1}$. The two oblique lines show a portion of the swath shown in Fig. 5(f) and indicate the region used in constructing the Hovmüller diagram shown in Fig. 18.
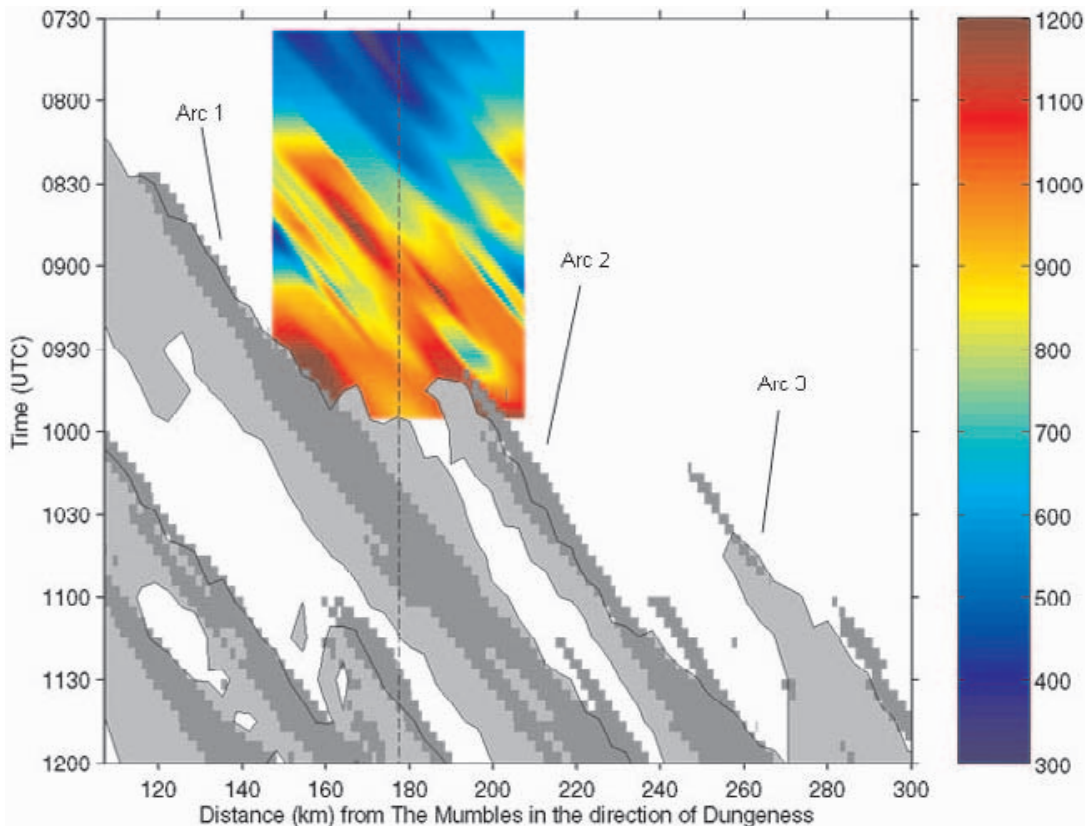

Figure 18. The inset is a Hovmüller diagram of height of boundary-layer top (colour, from 300 to $1200 \mathrm{~m}$ ), estimated from plots like Fig. 17 derived using sets of RHI scans from the clear-air radar obtained every 23.3 minutes. This is embedded within a larger Hovmüller plot derived from Figs. 8 and 9 showing arcs of precipitation with rain-rate $>2 \mathrm{~mm} \mathrm{~h}^{-1}$ (dark grey shading) and cloud tops $>3.5 \mathrm{~km}$ (light grey shading). 

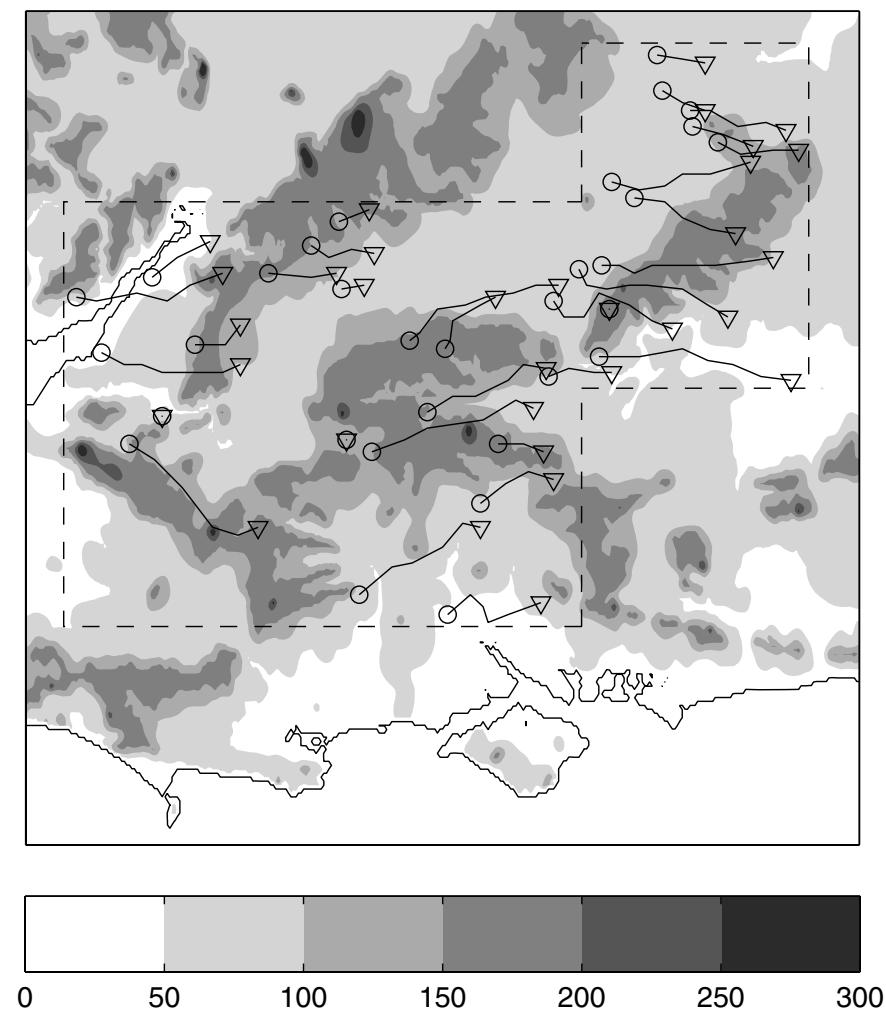

Figure 19. Location of first precipitation echoes (triangles) from cells within Arcs 1, 1a, 2 and 3, as detected by the weather radar network, and location of first identifiable cloud feature (circles) associated with that precipitation, as detected by the high-resolution visible MSG imagery, plotted on a map of terrain height (m, shading). Cell tracks are denoted by lines. The sub-region used in the statistical analysis shown in Fig. 20 is enclosed by the dashed line. The overall domain size is $190 \mathrm{~km} \times 190 \mathrm{~km}$.

above higher terrain. This tendency appears to be better defined for the overall cloudgrowth period than for the time of cloud initiation (circles). To test the validity of this impression we have carried out a simple statistical analysis.

Figure 20 shows three probability density distributions (p.d.f.s). The first (solid line) is for all the orography in the broad region where convective showers formed. This region is bounded by the dashed line in Fig. 19. The second distribution (dashed line) is for the orography directly below the trajectories, between cloud formation and detectable precipitation, shown in Fig. 19. The third distribution (dotted line) is for the orography below the location of cloud formation.

If the location of initiation or development of precipitating convection tended to occur over higher ground, then the corresponding probability density distributions should have peaks shifted towards elevated terrain. This is so to a limited extent, but the three distributions are on the whole rather similar, and have very similar statistical properties. This would occur if the second and third distributions were almost randomly generated subsets of the first. To complete the analysis, the 32 cloud tracks shown in Fig. 19 were randomly redistributed one thousand times within the region bounded by the dashed lines. For each of these redistributions, the p.d.f. of the orography below the cloud tracks was calculated. The spread in these one thousand p.d.f.s is indicated by the shading in Fig. 20, which has a width of one standard deviation each side of the mean. Although the sample size is still rather small, the fact that the p.d.f. for the 


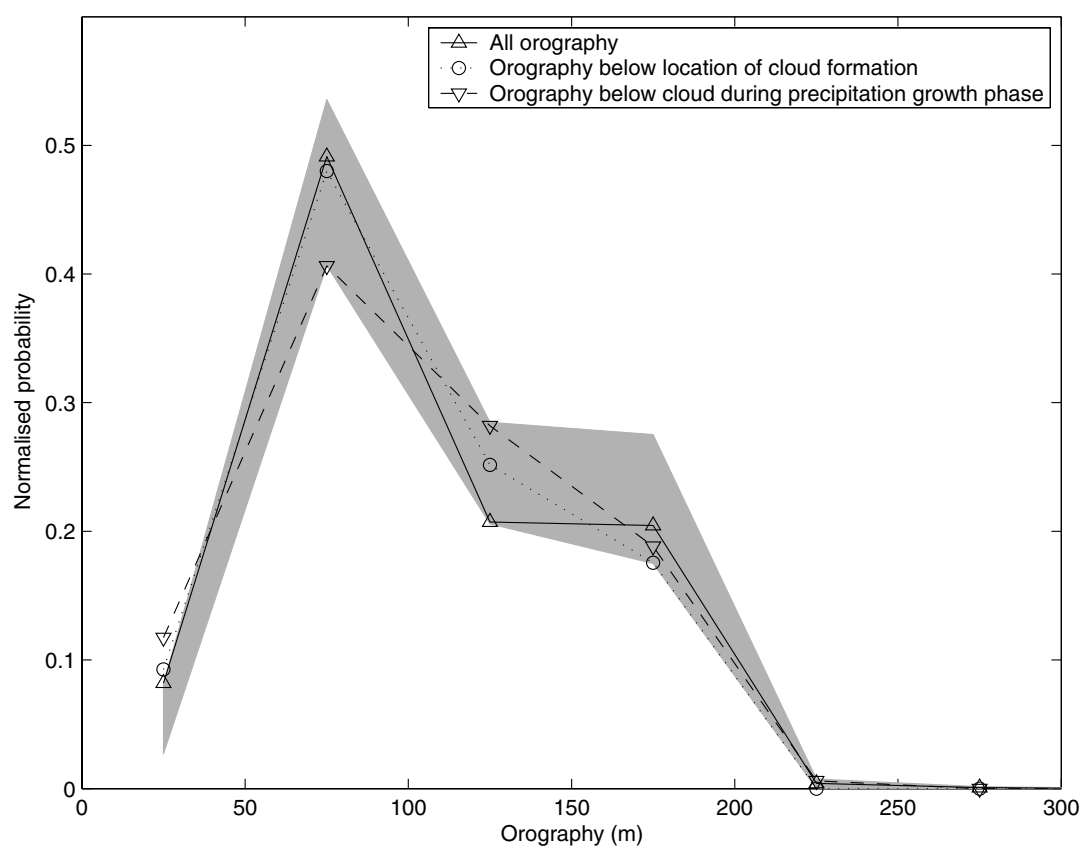

Figure 20. Probability density function (p.d.f.) for the orography in the region (bounded by the dashed line in Fig. 19) where the precipitating convection developed (solid line) directly underneath the trajectory of the cells during the precipitation growth phase (dashed line) and underneath the location of cloud initiation (dotted line). The spread in the p.d.f.s of 1000 random redistributions of the cell tracks over the same region is shown by grey shading of width one standard deviation each side of the mean. The orography is counted in $50 \mathrm{~m}$ bins.

observed cloud tracks lies wholly within the shaded region suggests that the location of convective initiation and precipitation development with respect to the underlying orography is statistically indistinguishable from a random distribution. This would suggest that the orography did not play a dominant role in determining the location of initiation of the convective cloud, or the subsequent development of the precipitation. This is consistent with the fact that the wave-like perturbation was apparently able to organize the convection into fairly well-defined arcs albeit with a limited degree of irregularity being imposed by other effects. It would also be consistent with the gravity wave having an effect over a deep layer while the effect of the topography in a neutral boundary layer diminishes rapidly with height above the ground.

\section{SYNTHESIS AND DISCUSSION}

We know from the observations from the clear-air radar and the wind profiler, described in section 3(e), that the air in the convective boundary layer, as it warmed up during the morning on 10 July, eventually broke through a stable layer or lid that was capping the boundary layer. We also know from the analysis of the clear-air radar scans in section 3(f) that the depth of the boundary layer was affected by a mesoscale perturbation; this perturbation appeared to be wave-like with a wavelength of roughly $40-50 \mathrm{~km}$. We shall consider the possible origin of this wave-like perturbation later. At this stage, however, the point we wish to stress is that, just prior to the convection breaking through, the vertical amplitude of the wave was about $\pm 150 \mathrm{~m}$. Such a vertical displacement, whatever its cause, will have affected the strength of the lid capping the 
boundary layer, with consequent effects on the initiation of convection. To examine these effects we shall now modify representative soundings by subjecting them to lifting of this magnitude.

The special radiosonde ascents planned for the main CSIP campaign were not available for the pilot project and so we improvised with soundings derived from the operational Met Office mesoscale model. We used soundings derived for the location of Larkhill which was within the region where the Arc 2 convection broke out. The largescale situation at Larkhill was fairly stationary around the time of this sounding, giving confidence in its representiveness. The mesoscale model performed well on this occasion, but even so, it is prudent as a general rule not to rely too much on the detail of model-derived soundings. The fact that we are now going to present a fairly detailed interpretation is justified on the grounds that the results are not only consistent with the observed evolution of the convection, but that, in any case, they are likely to be robust if regarded as a sensitivity analysis.

The tephigrams in Fig. 21 show just the lowest part (1000-800 hPa) of the modelderived soundings for Larkhill at 0700, 0800 and 0900 UTC. Shown for each time are the unmodified soundings on the left, soundings subjected to dry adiabatic lifting of $15 \mathrm{hPa}(150 \mathrm{~m})$ in the middle, and soundings subjected to dry adiabatic subsidence of $15 \mathrm{hPa}$ on the right. For simplicity, and since we are considering only a small height interval, constant lifting with height has been assumed. Shown in each case are the environmental profiles and a parcel ascending dry adiabatically and then pseudoadiabatically from $975 \mathrm{hPa}$. This level has been chosen as it represented the average properties of the lowermost unmodified layer, from 1000 to $950 \mathrm{hPa}$. Positive and negative areas, corresponding to positive and negative buoyancy (i.e. CAPE and CIN), are shown. A clear message that may be drawn from Fig. 21 is how sensitive the CIN is to lifting by as small a pressure as $\pm 15 \mathrm{hPa}$. In the unmodified soundings there was a small layer of CIN, with $-\Delta T$ up to $0.5 \mathrm{degC}$. The CIN (i.e. the lid capping the boundary layer) occupies the layer 975 to $870 \mathrm{hPa}$ at $0700 \mathrm{UTC}$, decreasing to 920 to $870 \mathrm{hPa}$ by 0900 UTC. In the places with $15 \mathrm{hPa}$ subsidence the CIN is much larger whereas, in the regions with $15 \mathrm{hPa}$ lifting, the CIN (i.e. the lid) is almost removed at 0800 UTC and it is entirely eliminated by 0900 UTC. This is consistent with the observed facts that (i) the Arc 2 convection broke through the stable lid between 0800 and 0900 UTC, and (ii) the Arc 2 convection broke out, roughly in a north-south line, within a crest of a wave that perturbed the stable lid by $\pm 150 \mathrm{~m}$.

It is instructive to summarize the growth history of the shower clouds by synthesizing a number of datasets on a single diagram as in Fig. 22. This is a Lagrangian time history for cells within Arc 2 as they travelled within the swath used to derive the earlier Hovmüller diagrams. It is based on values in Figs. 8, 9 and 18 read off on a diagonal strip along the axis of Arc 2, with a width of $30 \mathrm{~km}$ along the $x$-axis of the Hovmüller diagrams. As such, these values apply to the tallest Arc 2 clouds encountered at any given time within the swath drawn in Fig. 5(f) (see the bold dash-dot line in Fig. 22). Similarly, in the case of the height of the boundary-layer top, the bold solid blue line in Fig. 22 refers to the height of the region from which the clouds developed. In the case of the rainfall rate, the green histogram refers to the heaviest showers that were being produced at any given time.

Also shown in Fig. 22 are the heights of the lifting condensation level (LCL) and level of free convection (LFC) inferred from the mesoscale model with alternative assumptions of zero lifting and $150 \mathrm{~m}$ lifting overall. The spatial variability in refractive index over the area within about $20 \mathrm{~km}$ from Chilbolton, derived from the clear-air radar using the Fabry et al. (1997) technique, was very small (not shown); it implied variations 
Time

(UTC) Original profile
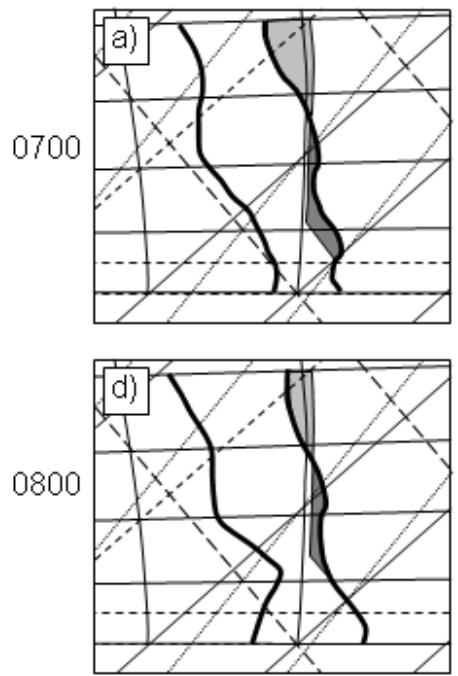

0800

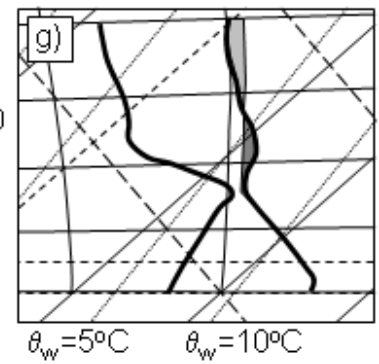

Lifted by $15 \mathrm{hPa}$
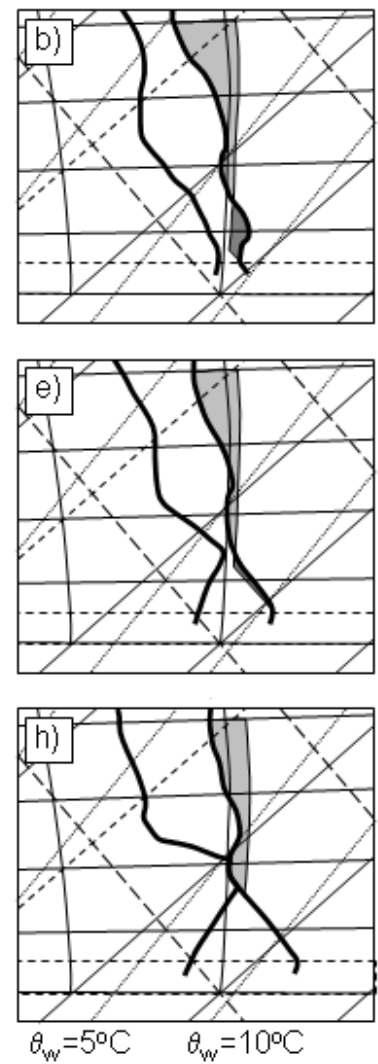

Lowered by $15 \mathrm{hPa}$
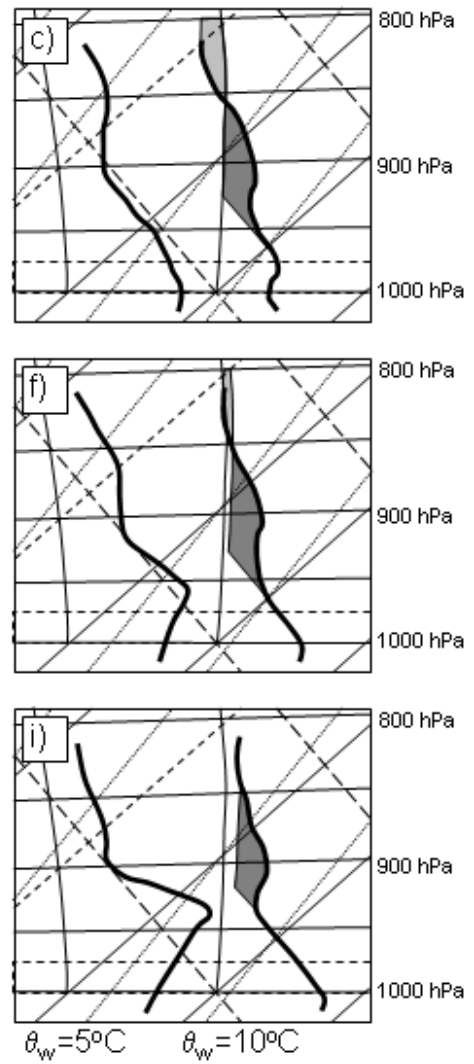

Figure 21. Tephigrams for Larkhill at $0700 \mathrm{UTC}$ showing a region near the surface (from 1000 to $800 \mathrm{hPa}$ ) and centred on the $\theta_{\mathrm{w}}=10^{\circ} \mathrm{C}$ line, derived from the forecast run from the Met Office $12 \mathrm{~km}$ mesoscale model started at 0000 UTC on 10 July 2004: (a) the unmodified profile (b) the profile lifted dry-adiabatically by $15 \mathrm{hPa}$, and (c) the profile lowered dry-adiabatically by $15 \mathrm{hPa}$. (d)-(f) and (g)-(i) are as (a)-(c), but for 0800 and $0900 \mathrm{UTC}$, respectively. The positive area (CAPE) and negative area (CIN) for a parcel lifted from $975 \mathrm{hPa}$ are shaded light and dark grey, respectively.

in relative humidity close to the ground of less than about $\pm 5 \%$. The associated variability in the heights of the LCL and LFC for the unmodified soundings are represented in Fig. 22 by blue and pink shading, respectively. Overall, the heights of the LCL and LFC were not very sensitive in the model to variations in low-level humidity. The LCL, at $700 \mathrm{~m}$, was also insensitive to overall lifting after 0800 UTC and so Fig. 22 suggests that the first cumulus should have been observed close to 0810 UTC as the top of the convective boundary layer reached this level (see label (1) in Fig. 22). We should, of course, be cautious about taking the model output too literally; on the other hand, observations from a ground-based time-lapse camera at Chilbolton do support this interpretation, with clear skies at low level seen at 0800 UTC, but scattered cumuli being evident by 0820 UTC (Figs. 23(a) and (b)).

In Fig. 22, the lower bound of the grey shaded region, which coincides with the bold black dash-dot line, represents the cloud-top height derived from the infrared MSG imagery assuming the cloud fills the footprint. However, the upper bound of the grey shaded region (labelled (1), (2) and (3)) is thought to be a more realistic estimate of cloud height, taking into account the underfilling of the satellite footprint by individual 


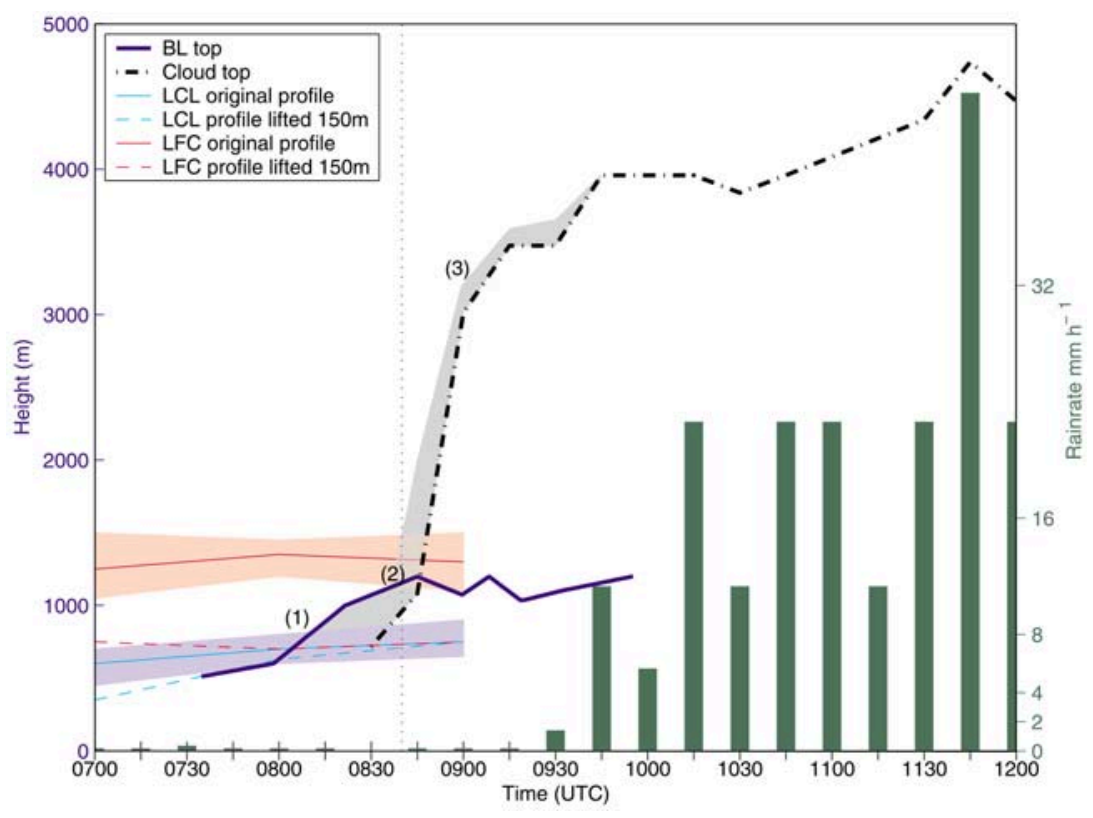

Figure 22. Composite time-height diagram summarizing the initiation of convection within Arc 2. The observed maxima of boundary-layer height ( $\mathrm{m}$, bold blue line), cloud-top height ( $\mathrm{m}$, bold black dash-dot) and precipitation rate $\left(\mathrm{mm} \mathrm{h}^{-1}\right.$, green histogram) are shown as a function of time, calculated over the width of the arc within the swath shown in Fig. 5(f). The lifting condensation level (LCL) and level of free convection (LFC), derived from the mesocale model soundings, for both unmodified profiles and profiles that have been lifted by $150 \mathrm{~m}$, are shown by thin blue and red lines respectively between 0700 and 0900 UTC. The coloured shading around the LCL and LFC represents the variation in height, for the unmodified profiles, associated with the $\pm 5 \%$ relative humidity variation inferred from the clear-air refractivity measurements. The vertical dotted line at 0840 UTC denotes the time when penetrative convection broke through the lid capping the boundary layer. Labels (1), (2) and (3) and the grey shading are explained in the text.

clouds which would have been particularly severe during the early growth of the clouds. Although the precise position of the upper bound drawn in Fig. 22 is rather arbitrary, it does satisfy the following constraints. First of all, position (1) corresponds to when the observed depth of the boundary layer first reached the LCL derived from the model and the first small cumulus clouds were observed to appear. Then, for the next 30 minutes or so (up to position (2)), the cumulus tops would have coincided with the rising boundarylayer top, even though at this time the clouds were still too small to be detected by the MSG satellite.

The time-lapse camera situated at Chilbolton captured the early development of the deeper convection, starting at around 0840 UTC. Figure 23(c), at 0843 UTC, shows deepening cumulus congestus cloud located behind some shallow cumulus. By 0856 UTC, one of these clouds has deepened considerably and can still be seen behind some nearer lower-level clouds (Fig. 23(d)). This is consistent with Fig. 22, which shows the convection breaking through the lid capping the boundary layer at about 0840 UTC (position (2)). The boundary-layer top at this time would have been 0 to $300 \mathrm{~m}$ below the LFC in the absence of any overall lifting (see Fig. 22), but about 200 to $500 \mathrm{~m}$ above the LFC assuming overall lifting of $150 \mathrm{~m}$. (The range of heights for these two levels due to the variability in relative humidity are not shown in Fig. 22.) A literal interpretation of this would imply that even lifting by somewhat less than $150 \mathrm{~m}$ would have been sufficient to trigger the observed penetrative convection. 

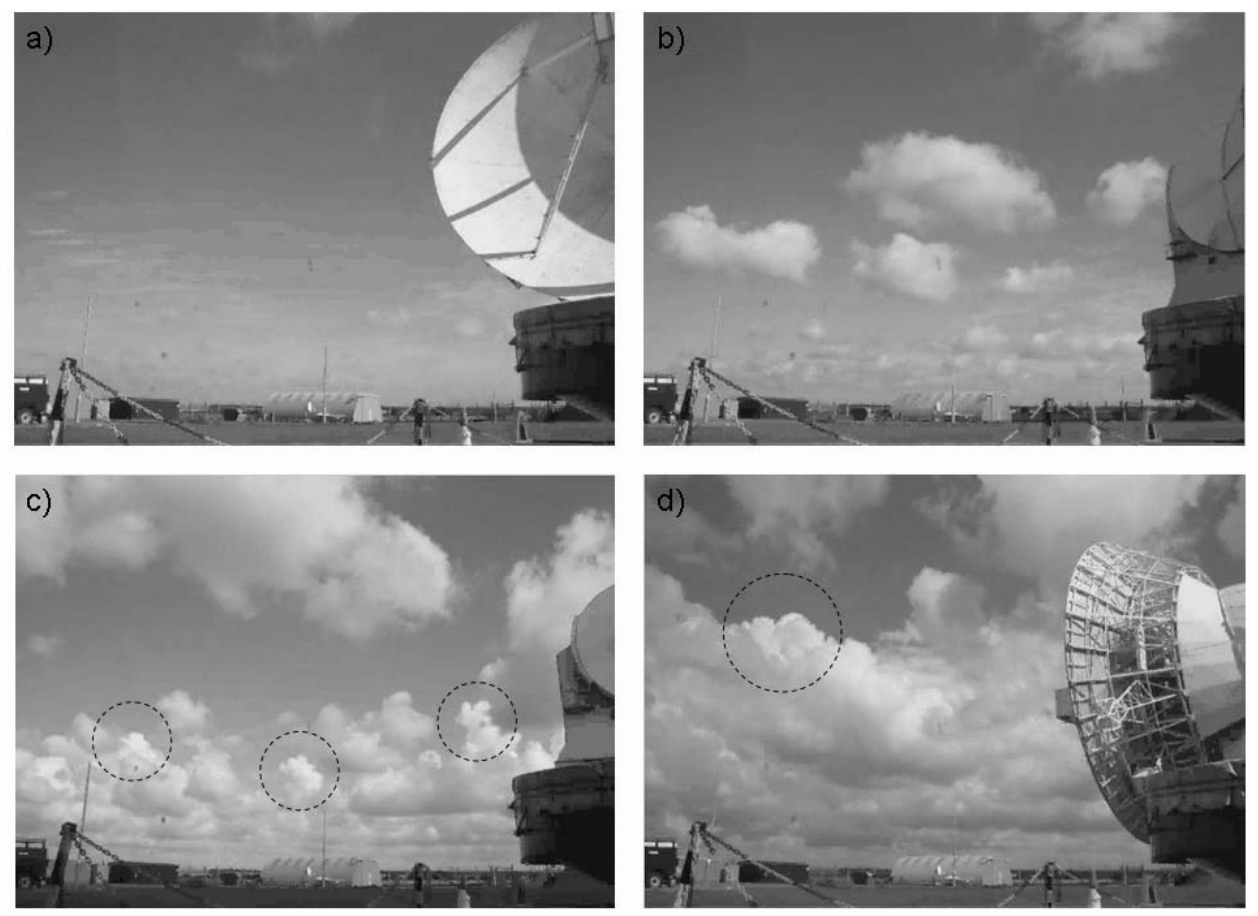

Figure 23. Cloud photographs from ground-based camera at Chilbolton, looking north: (a) 0800 UTC, relatively clear sky with no low-level cloud, (b) 0820 UTC, scattered cumuli, (c) 0843 UTC, early stages of deepening convection visible in the background (see dashed rings), and (d) 0856 UTC, deeper convection visible behind the nearer low-level clouds (see dashed ring).

After position (2) the tops of the penetrating convection rose more rapidly until 0900 UTC, position (3). Between positions (2) and (3) the individual clouds were at first very small in the horizontal but, by 0900 UTC, Fig. 16(c) shows that the tallest clouds were about $2 \mathrm{~km}$ wide and so the underfilling of the footprint and underestimation of the cloud-top height would have been less, qualitatively in line with Fig. 22, where the upper bound of the grey shaded region is shown tending towards the values derived from the MSG infrared imagery. The first rain was detected half an hour later, at 0930 UTC.

We speculate that the $40-50 \mathrm{~km}$ wavelength perturbation to the boundary layer may have been due to gravity waves. The source of these waves could either have been the updraught associated with the convection in the primary storm, or the forced ascent at the Arc 1 gust front. However, a proper assessment of the plausibility of gravity waves being the cause of the observed perturbation calls for idealized numerical modelling simulations. These simulations should, amongst other things, examine the dependence of the horizontal propagation speeds and the horizontal wavelength on the vertical thermodynamic and shear profiles. Such an assessment is presented in a companion paper by Marsham and Parker (2006).

\section{CONCLUDING DISCUSSION}

The results presented in this paper are from a case-study of the initiation of some relatively weak summertime showers and thunderstorms that broke out in southern Britain in a polar maritime airmass. This is a common scenario for Britain; it is one that is characterized not only by modest CAPE and wind shear but also-and this 
is particularly important from the point of view of convective initiation-by weak convective inhibition, or CIN. In such circumstances one might expect that, as the boundary layer experienced its diurnal warming trend, the convection would be triggered readily, and in a rather disorganized way, by small topographical effects such as those caused by the $200 \mathrm{~m}$ high hills in central southern England where the study was focused. Our statistical analysis showed no clear preference for the initial growth of the shower clouds to occur over the hills. Instead, the dominant triggering mechanism was one which imposed on the resulting convection a banded structure unrelated to the orientation of the topography. This is the main theme of the case-study.

In field campaigns, one's choice of case-study is often dictated by serendipitous circumstances. In this case the serendipity was the occurrence of a multiply banded organization in the initiating convection combined with the fact that the initiation took place within close range of the Chilbolton clear-air radar. Thus, despite the limited range capability of this radar, it was able to provide a useful description of the initiating convection.

Three initiating bands of convection were studied (called Arcs 1, 2 and 3) and one of these (Arc 2) developed in a line passing almost overhead of the radar which detected convective elements reaching $3 \mathrm{~km}$ within 20 minutes of their breaking through the top of the boundary layer. The clear-air radar observed a wave-like modulation in the depth of the boundary layer long before the convection started to develop. The first precipitation in Arc 2 was detected at 0945 UTC, but one and a half hours before this, the top of the boundary layer was observed to vary spatially, being at almost $900 \mathrm{~m}$ just upwind of where Arc 2 developed compared to only $600 \mathrm{~m}$ in places $20 \mathrm{~km}$ downstream. This was at a time when the boundary layer as a whole was deepening steadily as a result of solar heating. A further forty minutes before this, the height of the boundarylayer top had varied from about $600 \mathrm{~m}$ in the region of the atmosphere which gave rise to Arc 2, to only $300 \mathrm{~m}$ in the region $20 \mathrm{~km}$ downstream. At the same time, but $20 \mathrm{~km}$ ahead, the depth increased to $600 \mathrm{~m}$ again; this was in a region of the atmosphere where another parallel band of convection (Arc 3) subsequently developed. In summary, the variation in the depth of the boundary layer just before the convection in Arcs 2 and 3 was initiated was in the form of a wave-like perturbation with amplitude $\pm 150 \mathrm{~m}$ and horizontal wavelength about $40-50 \mathrm{~km}$.

The hypothesis, then, is that lifting of as little as $150 \mathrm{~m}$ by such a wave disturbance was sufficient to trigger the convection along lines near Chilbolton. The plausibility of this hypothesis has been tested by examining the effect of lifting on model-derived soundings for the appropriate location. This small amount of lifting was indeed found to be sufficient to just remove the weak CIN (i.e. the lid capping the boundary layer) that characterized the occasion.

The question then arises as to the nature of the mesoscale lifting mechanism that locally removed the CIN. It has been shown that Arc 1 was probably triggered by the gust front (density current) at the leading edge of a cold pool associated with an earlier cluster of showers referred to as the primary storm. Arc 1 itself went on to sustain the density current, which propagated at the same speed as the rain band itself, but this could not have been directly responsible for triggering Arc 2, which formed as much as $40 \mathrm{~km}$ ahead of it. Similarly, Arc 2 may have developed a gust front but it could not have played a role in the triggering of Arc 3 which began forming even before the first precipitation was detected from Arc 2.

The question remains as to what did generate the wave train that triggered Arcs 2 and 3. A possible cause is a gravity wave generated by the cluster of convective showers that formed predominantly close to the coast of south-east Wales in the early 
morning between 0530 and 0800 UTC and which we refer to collectively as the primary storm. Because this wave train appeared to travel at a velocity comparable with the resulting convective clouds, they remained roughly in phase, thereby reinforcing their continued development, rather than triggering convection outside of the cloud arcs. Such reinforcement was not possible in the case of stationary terrain effects.

A seemingly anomalous occurrence was a short line of convective showers (Arc 1a) that formed between Arcs 1 and 2, and eventually became subsumed by Arc 1. The Arc 1a convection formed between two main arcs where one would expect a simple gravity wave train to have suppressed convection. However, there were rather large gaps between the radar observations of boundary-layer depth and one cannot dismiss the possibility of a locally elevated boundary layer in this location. This would suggest a rather complex situation, with gravity waves of different wavelengths perhaps emanating from different sources.

A numerical modelling study is required to make further progress. This has been carried out by Marsham and Parker (2006) and is presented as part II of this paper. They use the Met Office large-eddy model to study the waves generated by an idealized representation of the primary storm. The modelled storm generated a cold pool, which tended to give secondary initiation on the downwind side of the storm, as observed. Marsham and Parker (2006) also show that the primary storm may have generated gravity waves, which at first suppressed and then initiated convection downwind of the primary storm. In their simulation, non-hydrostatic wave dispersion gave multiple wave maxima, which may have generated the distinctive arcs of convection observed to the east of the primary storm.

\section{ACKNOWLEDGEMENTS}

We wish to thank everyone else who participated in the CSIP pilot project, including Lindsay Bennett, Karl Beswick, Barbara Brooks, Chris Collier, Fay Davies, Martin Gallagher, Wendy Garland, Anthony Illingworth, Charles Kilburn, John Marsham, Doug Parker, Nigel Roberts, Ann Webb, Geraint Vaughan and Charles Wrench. The CSIP logo that appears in Fig. 1 was designed by Gerard Devine. Thanks are due to Robin Hogan for his help in processing the radar data shown in Figs. 10 and 16. Thanks are due to the Met Office for the radar network rain-rate data, and for the mesoscale model forecast data used in producing the Larkhill soundings. Thanks are also due to Eumetsat for the Meteosat-8 high-resolution visible and infrared channel data. The project exploited new instruments available through the Universities' Facility for Atmospheric Measurement (UFAM) which is funded by the Natural Environment Research Council following an initial award from the HEFCE Joint Infrastructure Fund. Operational observational data were provided by the Met Office. The Chilbolton Observatory, around which the project is based, is managed by John Goddard and owned by the Council for the Central Laboratory of the Research Councils.

\section{REFERENCES}

Barnes, S. L.

Fabry, F., Frush, C., Zawadzki, I. and Kilambi, A.

Goddard, J. W. F., Eastment, J. D. and Thurai, $\mathrm{M}$.
1964 A technique for maximizing details in numerical weather map analysis. J. Appl. Meteorol., 3, 396-409

1997 Extracting near-surface index of refraction using radar phase measurements from ground targets. J. Atmos. Oceanic Technol., 14, 978-987

1994 The Chilbolton Advanced Meteorological Radar: a tool for multidisciplinary atmospheric research. Electron. Commun. Eng. J., 6, 77-86 
Marsham, J. H. and Parker, D. J.

Norton, E. G., Vaughan, G., Methven, J., Coe, H., Brooks, B., Gallagher, M. W. and Longley, I.

Schmetz, J., Pili, P., Tjemkes, S., Just, D., Kerkmann, J., Rota, S. and Ratier, A.

Smith, R. K., Crook, N. A. and Roff, G.

Weckwerth, T. M., Parsons, D. B., Koch, S. E., Moore, J. A., LeMone, M. A., Demoz, B. B., Flamant, C., Geerts, B., Wang, J. and Feltz, W. F.

Wilson, D. R., Illingworth, A. J. and Blackman, T. M.
2006 Secondary initiation of multiple bands of cumulonimbus over southern Britain. II: Dynamics of the secondary initiation. Q. J. R. Meteorol. Soc., 132, 1053-1072

2005 Boundary layer structure and decoupling from synoptic scale flow during NAMBLEX. Atmos. Chem. Phys. Discuss., 5, 31913223

2002 An introduction to Meteosat Second Generation (MSG). Bull. Am. Meteorol. Soc., 83, 977-992

1982 The Morning Glory: an extraordinary atmospheric undular bore. Q. J. R. Meteorol. Soc. 108, 937-956

2004 An overview of the international $\mathrm{H}_{2} \mathrm{O}$ project (IHOP-2000) and some preliminary highlights. Bull. Am. Meteorol. Soc., 85, 253-277

1995 The use of Doppler and polarisation data to identify ground clutter and anaprop. Pp. 574-583 in COST 75 Weather Radar Systems, EUR 16013 EN, Ed. C. G. Collier 